Florida International University FIU Digital Commons

$5-22-2008$

\title{
The impact of standards-based practices in mathematics on the achievement of low- performing students
}

Marcus V. Anglin

Florida International University

DOI: $10.25148 /$ etd.FI14032321

Follow this and additional works at: https://digitalcommons.fiu.edu/etd

Part of the Curriculum and Instruction Commons

\section{Recommended Citation}

Anglin, Marcus V., "The impact of standards-based practices in mathematics on the achievement of low-performing students" (2008). FIU Electronic Theses and Dissertations. 1291.

https://digitalcommons.fiu.edu/etd/1291 
FLORIDA INTERNATIONAL UNIVERSITY

Miami, Florida

THE IMPACT OF STANDARDS-BASED PRACTICES IN MATHEMATICS ON THE ACHIEVEMENT OF LOW-PERFORMING STUDENTS

A dissertation submitted in partial fulfillment of the

requirements for the degree of

DOCTOR OF EDUCATION

in

EDUCATIONAL ADMINISTRATION AND SUPERVISION

by

Marcus V. Anglin

2008 
To: Interim Dean Kingsley Banya

College of Education

This dissertation, written by Marcus V. Anglin, and entitled The Impact of StandardsBased Practices in Mathematics on the Achievement of Low-Performing Students, having been approved in respect to style and intellectual content, is referred to you for judgment.

We have read this dissertation and recommend that it be approved.

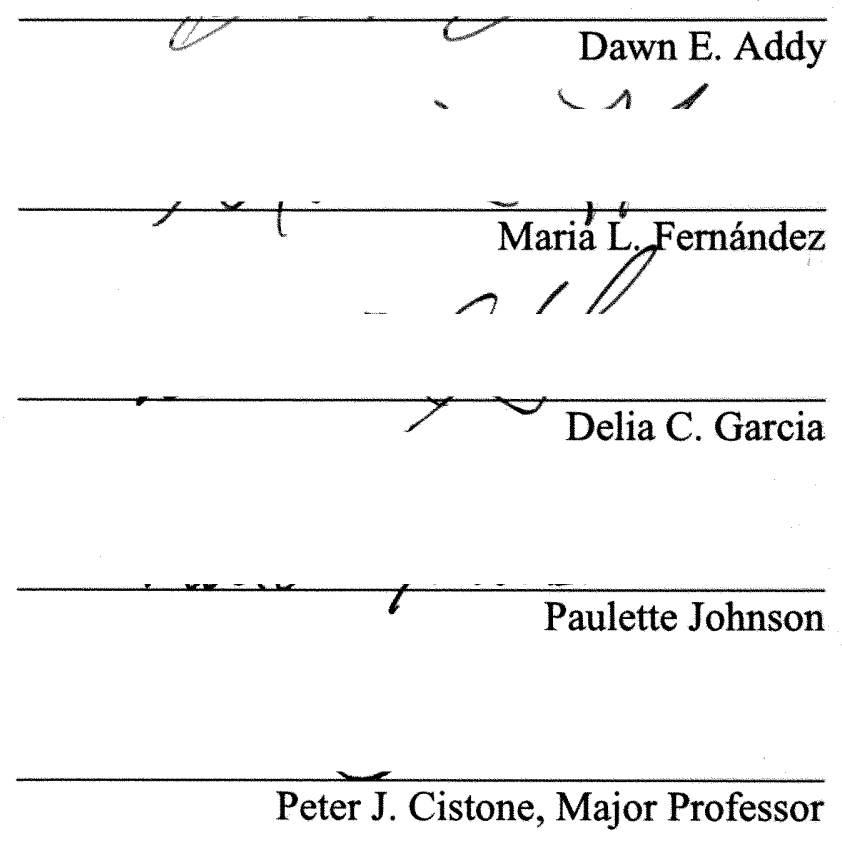

Date of Defense: May 22, 2008

The dissertation of Marcus V. Anglin is approved.

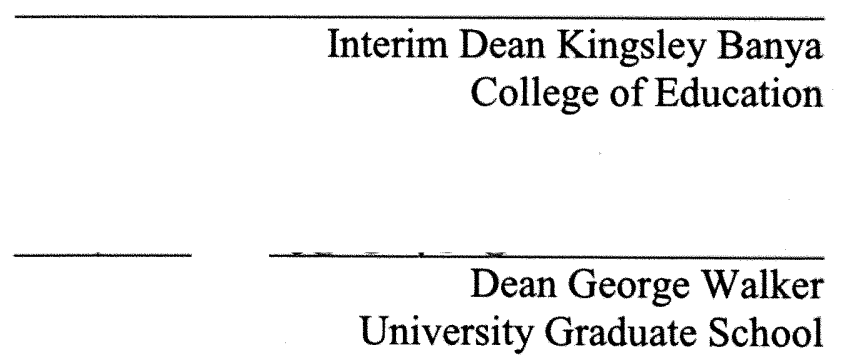

Florida International University, 2008

ii 
(C) Copyright 2008 by Marcus V. Anglin

All rights reserved. 


\section{DEDICATION}

I dedicate this dissertation to my parents, Victor and Mavis Anglin. They had always reinforced the phrase:

"Silver and gold will vanish away, but a good education will never decay." 


\section{ACKNOWLEDGMENTS}

I wish to thank the members of my dissertation committee: Dr. Dawn E. Addy, Dr. Maria L. Fernandez, Dr. Delia C. Garcia, Dr. Paulette Johnson, and Dr. Peter J. Cistone for their support, patience, and perseverance. Their gentle but firm direction has been most appreciated. Dr. Peter J. Cistone was instrumental in making this doctoral process an enjoyable adventure.

Dr. Paulette Johnson's statistical expertise was also instrumental in deciphering the nuances of the data collected which ultimately gave me a better appreciation for data analysis. Dr. Johnson's detailed explanations were essential to many of the conclusions drawn in the study. Her patience with making the statistics understandable could not go unmentioned.

I must also thank Mrs. Eugenie Dunn, District Mathematics Supervisor, MiamiDade County Public Schools, for providing some of the essential professional learning opportunities for the teachers involved in this study. Mrs. Dunn spent several Saturdays working relentlessly with the teachers on reforming their instructional practices and exposing them to many of Robert Marzano's What Works in the Classroom strategies.

Finally, I wish to express my deep gratitude to Miami-Dade County Public Schools for providing me the opportunity to achieve my dream. 


\section{ABSTRACT OF THE DISSERTATION \\ THE IMPACT OF STANDARDS-BASED PRACTICES IN MATHEMATICS ON THE ACHIEVEMENT OF LOW-PERFORMING STUDENTS}

by

Marcus V. Anglin

Florida International University, 2008

Miami, Florida

Professor Peter J. Cistone, Major Professor

This study examined standards-based mathematics reform initiatives to determine if they would improve student achievement on the part of low-performing students. New curricula, the Carnegie Learning Cognitive Tutor ${ }^{\circledR}$, were provided for algebra and geometry students. The new instructional strategy relied on both the teacher-led instruction and the use of computers to differentiate instruction for individual students. Mathematics teachers received ongoing professional development to help them implement the new curricula. In addition, teachers were provided with ongoing support to assist them with the transformation of the learning environments for students using standards-based practices. This quasi-experimental (nonrandomized) study involved teachers in two matched urban high schools.

Analyses (ANCOVAs) revealed that the experimental group with an appropriately implemented program had significantly higher learning gains than the comparison group as determined by the students' 2007 mathematics Developmental Scale Score (DSS). In addition, the experimental group's adjusted mean for the second interim mathematics assessment was significantly higher than the comparison group's mean. The findings 
support the idea that if the traditional curriculum is replaced with standards-based curriculum, and the curriculum is implemented as intended, low-performing students may make significant learning gains.

With respect to the teaching practices as observed with the Classroom Observation Protocol (COP), $t$-tests were conducted on four constructs. The results for both the algebra and geometry teachers on the constructs were not significant. The COP indicated that teachers in both the experimental and comparison groups used traditional instruction strategies in their classrooms. The analyses of covariance (ANCOVA) on the use of technology revealed no significant main effects for computer use. 


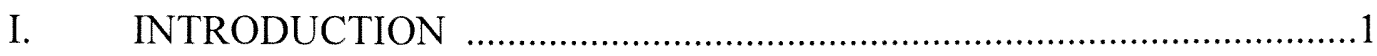

Definitions and Operational Terms..........................................................

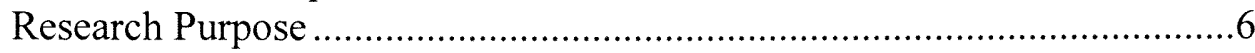

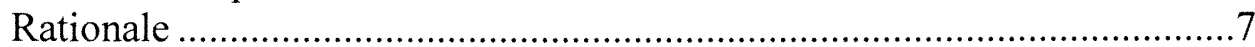

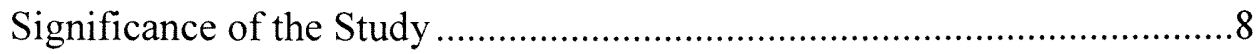

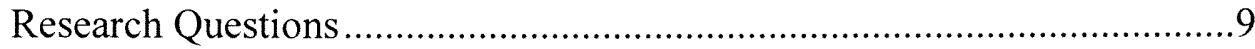

Organization of the Remaining Chapters..................................................

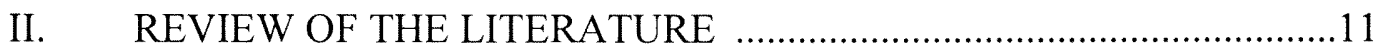

Current Student Performance................................................................11

The Reasons for Low Performance.............................................................12

Standards-Based Reform and the Mathematics Classroom ......................19

Key Principles of Implementing Mathematics Reform .............................21

Results of Standards-Based Curricula Implementation ...............................30

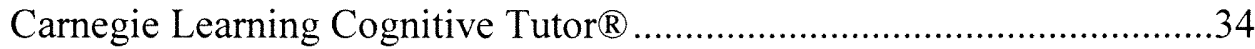

Dissenting Voices to Standards-based Practices.........................................39

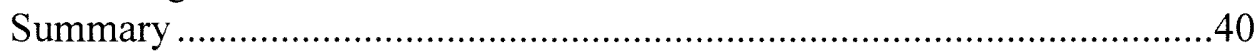

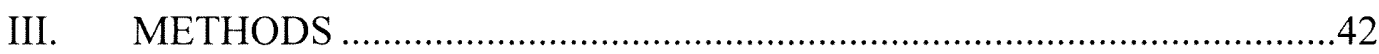

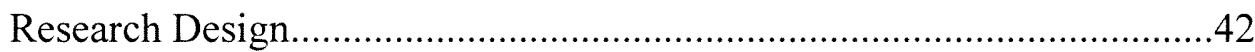

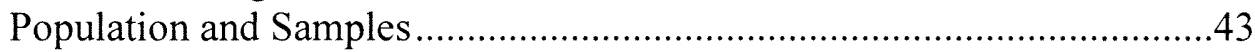

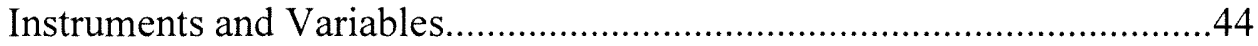

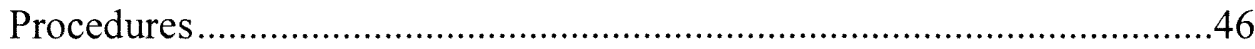

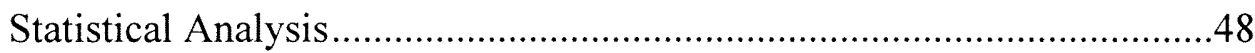

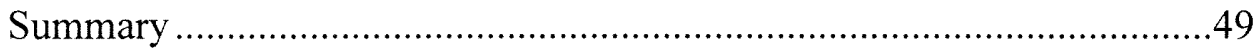

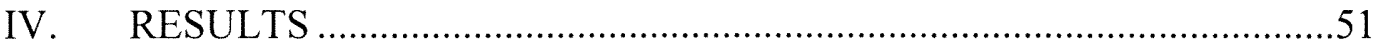

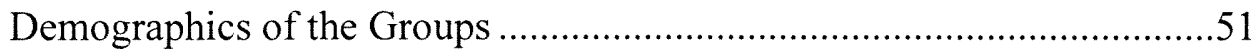

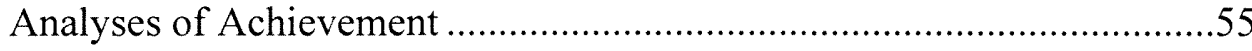

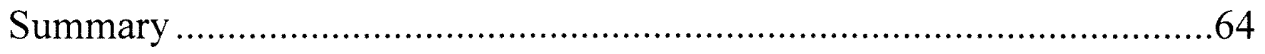

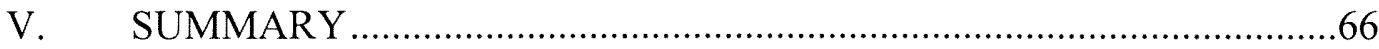

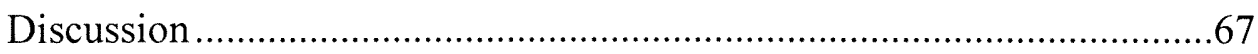

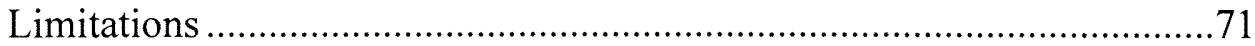

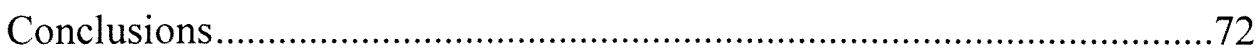

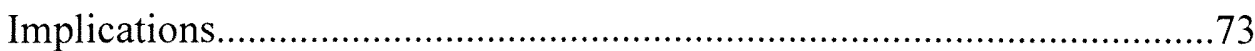

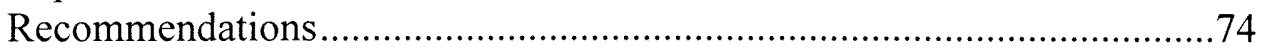




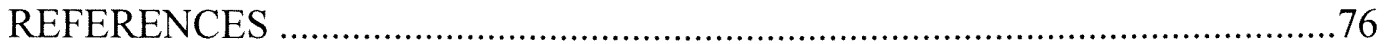

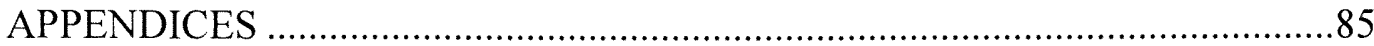

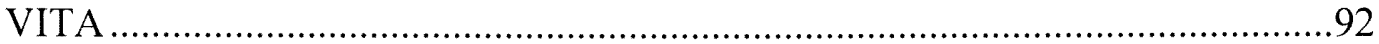




\section{LIST OF TABLES}

TABLE

PAGE

1. Instructional Materials Developed with National Science Foundation Funding

2. Demographic Distribution of Ninth-Grade Algebra Students 52

3. Demographic Distribution of Tenth-Grade Geometry Students 53

4. Adjusted Means and Standard Errors for Ninth-Grade Students' Second Interim Mathematics Assessment

5. Adjusted Means and Standard Errors for Tenth-Grade Students' Second Interim Mathematics Assessment

6. Adjusted Means and Standard Errors for Ninth-Grade Students' 2007 Developmental Scale Score Growth.

7. Adjusted Means and Standard Errors for Tenth-Grade Students' 2007 Developmental Scale Score Growth

8. Frequency of Computer Use for Experimental Group in Grades 9 and 10

9. Mean Scores of the Classroom Observation Protocol (COP) of NinthGrade Teachers

10. Mean Scores of the Classroom Observation Protocol (COP) of TenthGrade Teachers 


\section{CHAPTER I}

\section{INTRODUCTION}

The No Child Left Behind Act of 2001 (NCLB) signed into law by President George W. Bush on January 8, 2002, was the fundamental catalyst for a new era of accountability in mathematics and reading. NCLB is the most sweeping reform of the Elementary and Secondary Education Act (ESEA) which was enacted in 1965. It redefined the federal role in $\mathrm{K}-12$ education and was intended to close the achievement gap between disadvantaged and minority students and their peers. The NCLB Act is based on four key principles: stronger accountability for results, increased flexibility and local control, expanded options for parents, and an emphasis on teaching methods that have been proven to work. The stated intent of NCLB is to ensure that all children have a fair, equal, and significant opportunity to obtain a high-quality education and reach proficiency regarding the state's challenging academic achievement standards and academic assessments.

NCLB requires states to set annual objectives for all schools and districts that identify the percentage of students who must be proficient in mathematics and reading. These objectives are based on the goal that $100 \%$ of students will be proficient by the year 2013-2014. Each state must define "adequate yearly progress" (AYP) by determining every year the achievement of each school district and school. All students and eight identified subgroups (each of five race/ethnicity groups, students receiving free or reduced-price lunch, students who are limited English proficient (LEP), and students with disabilities) must meet the state's proficiency target in order for a school to achieve AYP. States must also produce annual state and school district report cards that inform 
parents and communities about state and school progress. Schools that do not make progress must provide supplemental services such as free tutoring or after-school assistance or taking corrective actions. If these schools are still not making adequate yearly progress after 5 years, they must make dramatic changes to their mode of operation.

In Florida, former Governor Jeb Bush instituted the Florida A+ Accountability System to grade schools and to determine AYP. Subgroups are required to have 30 or more students for inclusion in the AYP calculation at the school level. In addition, all schools must demonstrate a $1 \%$ improvement in the percentage of students proficient in writing, and high schools must also demonstrate a $1 \%$ improvement in their graduation rate. Schools or districts with subgroups that do not meet the annual objectives for reading or mathematics can meet AYP by reducing the proportion of non-proficient students in that subgroup by at least $10 \%$ from the prior year. No school rated as a "D" or "F" under the Florida A+ School Grading System can be classified as making AYP.

Miami-Dade County Public Schools (M-DCPS) is the largest school district in Florida and the fourth largest school district in the country. The 2005-2006 statistics that M-DCPS had 367 schools with more than 360,000 students and over 21,000 teachers (MDCPS, 2006). The racial/ethnic composition of the student population was $9.6 \%$ White Non-Hispanic, $27.6 \%$ Black Non-Hispanic, $60.4 \%$ Hispanic, and $2.4 \%$ comprised of other ethnic groups. Low performance of students on the mathematics section of the Florida Comprehensive Assessment Test (FCAT) and school performance ratings of "F" over consecutive years at several high schools indicate a need for additional curriculum and instructional support for mathematics teachers and students at all schools. 


\section{Definitions and Operational Terms}

There are several acronyms and phrases used throughout this study that will be defined in this section.

Achievement Levels on the Florida Comprehensive Assessment Test (FCAT)

Based on a Scale Score, a student achieves one of five possible levels. The Scale Score that a student could achieve in each subject area ranges from 100 to 500 .

Level 5. Performance at this level indicates the highest achievement. A level 5 student has success with the most challenging content of the Sunshine State Standards (SSS) and correctly answers most of the test questions.

Level 4. Performance at this level indicates that the student has success with the content of the SSS and correctly answers many of the most challenging test questions.

Level 3. Performance at this level indicates that the student has partial success with the content of the SSS and correctly answers many of the questions but is generally less successful with the most challenging questions.

Level 2. Performance at this level indicates that the student has limited success with the challenging content of the SSS.

Level 1. Performance at this level indicates that the student has little success with the challenging content of the SSS.

\section{Florida A+ Accountability System}

This is a single statewide accountability system adopted for all public schools in Florida that includes multiple measures. These include adequate yearly progress as defined by the No Child Left Behind Act of 2001, school grades, individual student progress towards annual learning targets to reach proficiency, and a return on investment 
measure that links dollars spent to student achievement. All schools are rated on each of these measures. Schools meeting all standards are designated as highly effective and efficient.

Florida Comprehensive Assessment Test (FCAT)

The FCAT is part of Florida's effort to improve the teaching and learning of higher educational standards. The primary purpose of the FCAT is to assess student achievement of the higher-order cognitive skills represented in the SSS in Reading, Writing, Mathematics, and Science. The SSS portion of FCAT is a criterion-referenced test. A secondary purpose is to compare the performance of Florida students to the reading and mathematics performance of students across the nation using a normreferenced test (NRT). Students in grades 3-10 take the Reading and Mathematics FCAT in the spring of each year. Students in grades 4,8 , and 10 take FCAT Writing, and FCAT Science is administered to all students in grades 5, 8, and 11. FCAT Developmental Scale Score (DSS)

A DSS has been created to help parents and others understand students' year-toyear progress. Developmental scores range from 0 to about 3000. Students should receive higher scores as they move from grade to grade, based upon their increased achievement. FCAT Mathematics Sunshine State Standards (SSS)

Mean scores are reported on a scale of 100-500. In addition, FCAT Mathematics SSS scores are reported in terms of five achievement levels (1-low to 5-high). Data includes mean scale scores and the percentage of students in each achievement level. 
FCAT Reading and Mathematics Norm-Referenced Test (NRT)

All students in grades 3-10 take the NRT section of the FCAT and receive scale scores that range from 424 to 863 across all grades. In addition, national percentile ranks (NPR), stanines, and content subscores are reported. The NRT section of the FCAT contains only multiple-choice questions. The NRT data include mean scale scores and median NPR scores. Content scores are included on the student, school, and summary reports provided to school districts.

Scale Scores

The FCAT SSS student report includes "scale scores" that range from 100 to 500 for the reading and the mathematics test. This scale is used for each grade tested; however, it is not easy to know whether a student has made progress using only the 100 to 500 score. For example, a fourth grader may earn a score of 280 in reading and the next year earn a score of 300 in 5 th-grade reading. It may look like the student made only a little progress but, in fact, the student probably made at least a year's worth of progress. Standards-Based Reform

In the early $1990 \mathrm{~s}$, a movement in education was established regarding standards of performance for public school students in pre-kindergarten to grade 12. This initiative evolved due to national concerns that United States (U.S.) students were not learning enough to compete in a global economy and that an intolerable gap existed between the achievement of minority and non-minority students. 
The Standards are skills and competencies that Florida students should be able to learn from an early age, as defined by a team of practicing classroom teachers, educational specialists, business people, and concerned citizens from Florida.

\section{Research Purpose}

The purpose of this study was to examine whether standards-based reform initiatives in M-DCPS mathematics classrooms improved low-performing student achievement (categorized as Level 1 and Level 2 status on the state's mathematics assessment) and closed the achievement gap between disadvantaged and minority students and their peers. To conduct this study, mathematics teachers received ongoing professional development to help them implement standards-based practices that support conceptual understanding and higher-order thinking skills. Teachers also learned how to implement new curricula that focused on constructivist ideas such as having students work in collaborative teams, cooperative teams, and problem-solving partnerships, along with the use of technology (computers and graphing calculators) to aid in the transformation of the learning environments of these students.

Principles and Standards for School Mathematics, a creation of the National Council of Teachers of Mathematics (NCTM, 2000), is intended to guide the way instruction is delivered (Vogler, 2002). The changes represent a departure from traditional techniques which emphasized memorization, manipulation of numbers, and procedural skill development (Riordan \& Noyce, 2001). In standards-based classrooms, problem solving, reasoning, writing, and conceptual knowledge are stressed with the intention of aligning standards with curriculum, instruction, and assessment (NCTM, 
2000). Recent research suggests that when standards-based practices are implemented, the performance gaps are reduced between majority and traditionally under-represented minority students and between low- and high-socioeconomic students (Schoenfeld, 2002). The theoretical framework that guided this study is based on the tenets of NCTM's Principles and Standards for School Mathematics.

\section{Rationale}

Educators have experienced difficulty identifying specific interventions (instructional programs) that result in significant increase in student achievement of lowperforming students. Researchers have identified specific teacher behaviors (high teacher expectations, use of cooperative groups, and the use of technology) that may increase student achievement (Davidson \& Kroll, 1991, Ferguson, 2003, Jaing \& McClintock, 2000, \& Tileston, 2004). However, few studies exist that clearly delineate how the integration of targeted instructional programs and best teaching practices can significantly increase the academic achievement of low-performing students. The rationale for this study was that there were reform-oriented programs at all levels (elementary, middle, and high school) that could enhance teaching practices and result in increased student achievement of low-performing students. The theory that guided this study was the belief that if low-performing students experienced reform-oriented curricula with sound teaching practices, these students would make significant learning gains.

In 1999, the U.S. Department of Education (DOE) Expert Panel on Exemplary and Promising Mathematics Programs released the Project 2061 report on standards-based reform programs. The Expert Panel looked for evidence of effectiveness, the quality of 
the curricula, and the level of teacher support. Programs that were rated promising or exemplary were said to contain both in-depth mathematics content and excellent instructional support. The curriculum that was chosen for this study, Carnegie Learning's Cognitive Tutor ${ }^{\circledR}$, was rated as one of the promising programs by the U.S. DOE Expert Panel. Carnegie Learning's Cognitive Tutor ${ }^{\circledR}$ instructional strategy relies on both the teacher-led instruction and the use of computers to differentiate instruction for individual students. This is designed to guarantee that every student would be responsible for making sense of the learning at his or her cognitive level without direct teacher intervention. The program is designed specifically to help reduce the teacher's burden of trying to meet the needs of the wide range of skills in each classroom.

\section{Significance of the Study}

The demands of state and federal accountability systems on the rating of schools in Florida make it imperative that educators research ways to increase the performance of students scoring at the lowest quartile in mathematics and reading. Curricula play a vital role in students' learning of mathematics. Valverde and Schmidt (1997) indicated that reports from the Third International Mathematics and Science Study (TIMSS) study signified that mathematics curricula in the U.S. lacked focus, did little to challenge students mathematically, and covered far too many topics with little depth. Along with curricula, effective instructional strategies and an environment that is conducive to learning are also paramount to increasing learning for all students. The effects that curriculum, instruction, and the classroom environment have on student achievement in mathematics programs are important and need to be further researched. This study 
attempts to identify certain key practices that can be linked to increased student achievement of low-performing students.

\section{Research Questions}

The study was based on the premise that reform-oriented practices rooted in standards-based curricula and instruction could improve mathematics achievement for low-performing students. Therefore, the following research questions were developed:

\section{Question 1:}

Is there a significant difference between the mathematics scores as measured by the district's second interim assessment of students taught by teachers using standardsbased curriculum and students taught by teachers using a traditional curriculum?

\section{Question 2:}

Is there a significant difference between the yearly growth in mathematics as measured by the FCAT Developmental Scale Scores (DSS) of students taught by teachers using standards-based curriculum and students taught by teachers using a traditional curriculum?

\section{Question 3:}

Is there a significant difference between the teaching practices as measured by the Classroom Observation Protocol (COP; Appendix A) of teachers using a standards-based curriculum and teachers using a traditional curriculum?

\section{Organization of the Remaining Chapters}

Chapter 2 examines the reasons for low student performance as well as the impact of the standards-based movement and how it has affected teaching practices and student achievement. It also examines how fidelity of implementation impacts student 
achievement as well as results of several standards-based programs at the high school level. Chapter 3 deals with the research design of the study and its methodology. Chapter 4 reports the descriptive statistics, inferential statistics, verification of hypotheses, and findings. Chapter 5 contains a general summary as well as recommendations for future studies. 


\section{CHAPTER II}

\section{REVIEW OF THE LITERATURE}

Research has suggested that what ensues in school can be a contributing factor when examining the reasons for low academic performance. Studies further indicate that standards-driven reform can result in increased achievement for low-performing students. This study attempted to determine the immediate and effective impact of standards-based practices on mathematics achievement of low-performing students. The problem was to investigate if teachers' implementation of new standards-based curricula and instruction, along with the use of technology, could positively transform the classroom environment of low-performing students and thus lead to increased achievement.

This review of the literature will focus on the following issues: (a) current student performance in the United States (U.S.), (b) the reasons for low student performance, (c) the current standards-based reform in the mathematics classroom, (d) key principles of implementing mathematics reform, (e) results of standards-based curricula implementation at the high school level, and (f) an examination of the curricula implemented in this study: Carnegie Learning: Cognitive Tutor ${ }^{\circledR}$ Algebra I and Geometry.

\section{Current Student Performance}

In general, many students in the U.S. are not achieving at high academic levels in mathematics or science (Bozick \& Ingels, 2008). The Third International Mathematics and Science Study (TIMSS) conducted in 1995 revealed that, compared to other students across the world, American students were not mastering higher standards (Schmidt, McKnight, Cogan, Jakwerth \& Houang, 1999). TIMSS examined the student 
performance and the teaching practices of 41 countries in the areas of mathematics and science. The results indicated that American students in grade 4 were achieving at a higher level than the international average, but American students in grades 8 and 12 were performing below the international average and at significantly lower levels of achievement than many other countries. The study was repeated in 1999 (TIMSS-R). Once again, the results indicated that American students were not performing as well as students in other developed nations. One implication of these studies is that if American students do not achieve at a higher level, they will not be able to compete in the global workforce.

An even more ominous problem exists when examining performance data for only American students. It indicates that there exists a large subgroup of students who are continuously classified as low performers. The Executive Summary on Narrowing the Achievement Gap (2003) identified a strong correlation between poverty and lowperforming students. In addition to poverty, the report also indicated other factors which contribute to student achievement, such as students' school experiences. These experiences are affected by a variety of issues such as the organization and management of the school, the qualifications of the teachers and other staff members, the level at which the subject matter and curriculum are taught, and the expectation level for all students. The failure to meet the needs of this large group of low-performing students could prove disastrous to the social and economic stability of the U.S.

The Reasons for Low Performance

There are numerous and complex reasons for the low performance of students. Factors such as parents' level of income and education are highly correlated with 
students' academic achievement (Edge \& Friedberg, 1984). Other factors such as poor student self-concept and prejudice can also play a role in student performance (Burn, 1998). However, factors related to schooling such as curricula, instruction, and classroom discourse could compound the problem even further. Research has shown that in many cases, schools may actually be the root cause why students are performing so poorly (Balfanz \& MacIver, 2000).

Kober (2001) found similar results. She observed that the students' low performance was not due to differences in innate ability, nor the result of biased test questions. Ethnic differences in parent income contributed to the low performance but did not entirely explain it. School factors that contributed to the differences in performance included limited participation of minority students in rigorous courses, watered-down instruction, less-qualified or experienced teachers, teachers with lower expectations, resource disparities between high-minority schools and other schools, concentrations of low-income and minority students in certain schools, school climate less conducive to learning, student performance anxiety, negative peer pressure, and disparities in access to high-quality preschool.

Community, home, and societal factors that contributed to the low performance included effects of poverty on learning, legacy of discrimination, limited learning supports in homes and communities, and access to parenting education. Corrective strategies for closing the low performance were increasing participation of minority students in challenging academic courses; investing in teacher professional development; implementing comprehensive, research-based models for school improvement; lowering class size in high-minority schools; expanding access to high-quality preschool programs; 
providing extended learning time and intensive supports for students who were having difficulty; and strengthening parent and community support for learning.

\section{Poor Student Self-Concept}

Many studies have shown that there is a link between self-confidence and academic success (House, 2000a). Bempechat, Graham, and Jimenez (1999) found that, regardless of ethnicity, high achievers were less likely to attribute failure to lack of ability. On the other hand, low achievers regularly attributed failure to lack of ability and success pertaining to external factors. Low achievers were less likely to make the connection between effort and success. This creates a cycle in which a continuous lack of effort leads to more failure. To break this cycle of failure, Marzano (2003) suggests that teachers use confidence-building techniques.

Studies have also shown that students' self-beliefs and academic background have been significant predictors of grade performance in college mathematics and science courses. Grade performance in introductory college chemistry was highly correlated to self-ratings of mathematical ability and overall academic ability (House, 1995a). Correspondingly, students' self-ratings of their mathematical ability, overall academic ability, and self-confidence in their intellectual ability were highly correlated to grade performance in introductory college mathematics (House, 1995b). Other results indicated that students' self-ratings of their overall academic and mathematical ability and their expectations of graduating with honors were significantly correlated with grade performance in college calculus (House, 1995c). Two studies revealed that students' selfconcept was significantly related to final grades in a college algebra course (Wheat, Tunnell, \& Munday, 1991) even after controlling for the effects of prior achievement 
(House, 1993). Another study showed that beliefs about mathematics difficulty on the part of students in a remedial college-level mathematics course were significantly related to final course grades (Stage \& Kloosterman, 1995). Additional evidence shows that students' attitudes and motivation may be related to their achievement in mathematics, and that accomplishment is then predictive of their continued enrollment in more advanced mathematics courses (Meece, Parsons, Kaczala, Goff, \& Futterman, 1982).

\section{Prejudice}

Covert and sometimes unintended prejudice can create an unhealthy culture for minority students. Steele (1999) defined "stereotype threat" (the fear of being viewed through the lens of stereotype or inadvertently confirming a stereotype) as a significant impediment to minority student achievement. In four quantitative meta-analyses conducted, Tenenbaum and Ruck (2007) found that teachers' expectations, referrals, positive and neutral speech, and negative speech differed toward ethnic minority students (i.e., African American, Asian American, and Hispanic) as compared with White students. Teachers were found to hold the highest expectations for Asian-American students. In addition, teachers held more positive expectations for White students than for Hispanic or African-American students. Teachers made more positive referrals and fewer negative referrals for White students than for Hispanic and African-American students. Although teachers directed more positive and neutral speech (e.g., questions and encouragement) toward White students than toward Hispanic and African-American students, they directed an equal amount of negative speech (e.g., criticism) to all students. In general, teachers' favoring of White students, compared with African-American and Hispanic students, was associated with small but statistically significant effects. The 
study suggests that teachers' expectations and speech vary with students' racial/ethnic backgrounds.

\section{Curricula}

According to Haycock (1998), schools can create a culture that believes not all students can learn. Therefore, some students are not given the same opportunities to achieve. In many urban elementary schools, children of color usually attend lowperforming schools that have less rigorous curricula (Schoenfeld, 2002; Secada, Fennema, \& Byrd, 1995). This can be compounded as these students move to the secondary level and find themselves being tracked into low-level courses that are not challenging (Calderon, 1999). However, studies such as the Algebra Project (Moses \& Cobb, 2001), Quantitative Understanding: Amplifying Student Achievement and Reasoning [QUASAR] (NCTM, 2000; Silver \& Stein, 1996), and Cognitively Guided Instruction (Fennema, Franke, Carpenter, \& Carey, 1993) signify that challenging mathematics programs (which emphasize conceptual understanding, problem solving, and communication) can be promising for minority students.

\section{Instruction}

Rowan, Chiang, and Miller (1997) suggest that a teacher's effect on student achievement can be attributed to three categories: (a) teaching ability defined in terms of the teacher's content knowledge; (b) teacher motivation, usually defined as teacher efficacy, locus of control, and outcome expectations; and (c) the school and classroom environment in which the teacher works, which includes such factors as the size of the classroom and the number of students in the class. 
Research suggests the profound impact of teacher content knowledge on the nature of instructional practice (Peterson, 1988; Shulman, 1986b). For example, sometimes teachers deliver the initial phase of their lessons and subsequently realize that they have not only introduced tasks that were causing confusion to themselves or to their students but that they do not necessarily know how to adjust the tasks. The result is a teacher-centered lesson. Thus a teacher-directed style of teaching becomes a mask for teachers who do not possess full knowledge of the content, students, and/or pedagogy. That is, without the demands arising from student input, teachers are free to impose the material on the students even when they themselves do not fully understand it or have inappropriately sequenced the material.

Teacher motivation or efficacy has been defined as teachers' "beliefs in their ability to have a positive effect on student learning" (Ashton \& Webb, 1986). Teacher efficacy has been correlated to significant variables such as classroom instructional strategies and willingness to embrace innovations. Inservice teachers and pre-service teachers who have high teacher efficacy use a greater variety of instructional strategies (Wenta, 2000). According to Woolfolk and Hoy (1990), teacher efficacy is considered as one of the few teacher characteristics that consistently relate to teaching and learning. Teachers that are highly efficacious are more likely to use inquiry and student-centered teaching strategies, while teachers considered to have low efficacy are more likely to use teacher-directed strategies such as lecture and reading from the text (Czernaik, 1990). In addition, teachers with high teaching efficacy are more likely to try new teaching strategies, particularly techniques that may be difficult to implement and involve risks such as sharing control with students. In evaluation of education projects by the Rand 
Corporation, it was found that teachers' sense of efficacy was positively related to the percentage of the project goals achieved, the number of teacher changes, the continuity of project materials and methods, and the level of improvement of student performance (Dembo \& Gibson, 1985).

\section{Classroom Discourse}

Discourse provides opportunities for students to share experiences that enable them to notice relationships of interest, to justify the relationships they observe, and to allow them to assume the responsibility for problem solving. Researchers in teaching and learning mathematics have called attention to the important attributes of tasks and verbal interactions in the classroom that are likely to influence the representations that students form and the connections they make (Behr, Harel, Post, \& Lesh, 1992; Mack, 1990). Discourse describes the verbal exchange between and among members of the classroom community—both teachers and students. It is the medium through which task engagement is facilitated for learning with understanding. It provides information about the standard for communication and teacher expectations. D'Ambrosio (1995) defines classroom discourse as the process of engaging the classroom community in real dialogue, wherein meaning is negotiated and assumptions are questioned.

Classroom discourse also has a profound effect on student achievement. Some teachers tend to engage low-performing students in lessons that require few or no higherorder thinking skills (Thompson, O'Quinn, \& North Carolina Education Research Council, 2001). This can further exacerbate the lack of effort or self-concept found in many low-performing students. Another fundamental problem is that as teachers use examples to convey meaning, they can use culturally-biased scenarios that are difficult 
for low achievers to understand (Bol \& Berry, 2005). For example, in a classroom discussion on perimeter and area, a teacher began the discussion around an island in the kitchen. However, none of the students who were from low socioeconomic status (SES) understood how an island could [literally] be in a kitchen. It was not until students actually verbalized the problem of an island being too big to fit in the kitchen did the teacher realize the students' confusion. It is important that teachers use a variety of strategies to impart the lessons so that they meet the needs of low achievers.

Standards-Based Reform and the Mathematics Classroom

The current standards-based reform movement embraces the belief that students' school experiences can offset the impact their socioeconomic status has on achievement. In fact, the standards-based movement posits that all children can learn and that schools control the factors to assure student mastery of a rigorous core curriculum (Grouws \& Cebulla, 2000). Responding to the standards-based movement, the National Council of Teachers of Mathematics (NCTM) produced four powerful and influential documents: Curriculum and Evaluation Standards for School Mathematics (1989), Professional Standards for Teaching Mathematics (1991), Assessment Standards for School Mathematics (1995), and Principles and Standards for School Mathematics (2000). These documents emphasized the need "for fundamental and meaningful changes not only in the content of mathematics courses, but in the way that they are taught and assessed" (Taylor, Campbell, \& Long, 2001, p. 44). This is evident in the six Principles (NCTM, 2000):

- Equity. Excellence in mathematics education requires equity - high expectations and strong support for all students. 
- Curriculum. A curriculum is more than a collection of activities: it must be coherent, focused on important mathematics, and well-articulated across the grades.

- Teaching. Effective mathematics teaching requires understanding what students know and need to learn and then challenging and supporting them to learn it well.

- Learning. Students must learn mathematics with understanding, actively building new knowledge from experience and prior knowledge.

- Assessment. Testing should support the learning of important mathematics and furnish useful information to both teachers and students.

- Technology. Scientific methods and materials are essential in teaching and learning mathematics; they influence the mathematics that is taught and enhance students' learning.

These principles were specifically put in place because too many students-especially students who are poor, non-native speakers of English, disabled, female, or members of minority groups-were typically victims of low expectations in mathematics.

In a study on the relationship between standards-based mathematics curricula and student achievement, Riordan and Noyce (2001) found that students being taught with standards-based curricula made significantly higher achievement gains than students using a traditional curriculum. These standards-based curricula gave materials to teachers that allowed and encouraged instructors to align their teaching and assessment practices with the NCTM Principles and Standards for School Mathematics (2000). 
In recent years, several studies have been conducted to illustrate the importance of standards-based reform in the elementary setting (Berry, 2003; Boaler, 2002; Hiebert, 1999). To further highlight the need for examining standards-based reform in middle schools, research findings show there is still a need for improving the teaching and learning of mathematics, especially in the middle grades. Contrary to the NCTM recommendations, most middle school mathematics teachers are still using drill-andpractice instructional techniques (Neiss, Erickson, \& Oregon State University, 1992). Furthermore, studies show that as much as $80 \%$ of the content in 7 th- and 8 th-grade mathematics courses in the U.S. was review from previous years (Flanders, 1994). At the high school level, tracking has consistently consigned disadvantaged groups of students to mathematics classes that concentrate on remediation or that do not offer significant mathematical substance. Standards-based reform is intended to give all students access each year they are in school to a coherent, challenging mathematics curriculum that is taught by competent and well-supported mathematics teachers.

Key Principles of Implementing Mathematics Reform The challenge of the standards-based reform movement is to effectively implement the key principles of the vision for mathematics called for in the standards within the classroom (Love, 2002). According to Weiss (1997), these principles include, but are not limited, to the following: (a) emphasizing high expectations for all students; (b) engaging students in meaningful activities that enable them to construct and apply their knowledge of key mathematics concepts; (c) using cooperative learning and techniques for asking questions that promote interaction and deeper understanding; 
(d) featuring appropriate, ongoing use of calculators, computers, and technologies; and

(e) focusing on in-depth learning of a limited number of powerful concepts and emphasizing understanding, reasoning, and problem solving rather than memorization of facts, terminology, and algorithms. Along with these key principles, almost all national standards, state frameworks, and local standards suggest basic changes in what teachers teach and how they instruct. These documents usually allude to high expectations, constructivist approaches, cooperative/collaborative practices, and the use of technology as the backbone of increasing student achievement.

\section{Emphasizing High Expectations}

Teachers' expectations, perceptions, and behaviors can sustain and even expand the gap in achievement between White and African-American students (Ferguson, 2003). Ferguson also suggests that effects of teacher expectations could be substantial if the effects accumulate from kindergarten to high school. Based on race, gender, and social class, teachers form different expectations of students and these expectations seem to be created in different ways (Baron, Tom, \& Cooper, 1985; Secada, 1992). In a study conducted by Jussim, Eccles, and Madon (1996), teacher expectations and perceptions had a significant effect on the grades and performance of sixth-graders on a standardized mathematics assessment. It showed that teacher expectations were almost three times greater for White than for African-American students, and the effects were also large for girls and low-income students. In their studies, Berry and Ritz (2004) indicated that middle school, African-American male students experienced lowered expectations from their mathematics teachers. They contended that these lowered expectations affected 
student achievement in mathematics and pupils' opportunities to gain access to high-level mathematics courses.

\section{Constructivist Approach}

Research on teaching and learning mathematics suggests the need for teaching practices based on constructivist views of learning (Boaler, 2002). The TIMSS video study shows that over $90 \%$ of mathematics class time in U.S. 8th-grade classrooms is spent practicing routine procedures, with the remainder of the time generally spent applying procedures in new situations. Literally, no time is spent inventing new procedures and analyzing unfamiliar situations. In contrast, students at the same grade level in typical Japanese classrooms spend approximately $40 \%$ of instructional time practicing routine procedures, $15 \%$ applying procedures in new situations, and $45 \%$ inventing new procedures and analyzing new situations. Research evidence suggests that students need opportunities for both practice and invention.

The findings from a number of research studies show that when students discover mathematical ideas and invent mathematical procedures, they have a stronger conceptual understanding of connections between mathematical ideas (Mack, 1990; Kamii \& Lewis, 1990). Constructivism is an ideology of education which encompasses an array of theoretical positions (Good, 1993) and has been used to refer to theories concerning learning, teaching, and curriculum development as well as the professional development of teachers (Hodson \& Hodson, 1998). The constructivist approach to teaching and learning mathematics explains how teachers can create environments in which students will formulate knowledge (Davis, Maher, \& Noddings, 1990; Kamii \& Lewis, 1990; Noddings, 2005). Vygotskii's (1986) zone of proximal development addresses how 
students working together, with adult guidance as needed and using proper tools, can construct this knowledge socially.

Traditional teaching practices are based on a behavioristic model of learning and have historically dominated the teaching of mathematics in the U.S. With this model, the teacher is the sage on the stage while the students sit passively and receive knowledge. The constructive model of learning, however, requires that the teacher function as a facilitator and the students actively engage in their own learning.

\section{Using Cooperative Learning}

One of the most popular instructional strategies in education is cooperative learning or small-group settings. Considerable research has been done which shows that within mathematics education, using small groups of various types for different classroom tasks has positive effects on student learning. The Davidson and Kroll (1991) review of the literature found that in 80 mathematics studies which compared student achievement in small-group settings with traditional whole-class instruction, more than $40 \%$ of students in small groups significantly outscored control students on measures of student performance. In 2 of the 79 studies, the control-group students performed better than the small-group students, and in those studies there were design irregularities.

From a review of 99 studies on cooperative group-learning methods at the elementary and secondary levels, Slavin (1990) determined that cooperative methods were effective in improving student achievement. Slavin also determined that smallgroup work had a positive effect on cross-ethnic relations and student attitudes towards school. In another review, Webb (1991) examined peer interaction and achievement in small groups (17 studies, grades 2-11) and found that highly structured small groups were 
positively related to achievement. He posited that group work was most effective when students were taught how to operate in units and how to give and receive help. The help was most effective when it was in the form of an elaborate explanation (not the answer) and then applied by the student either to a current problem or to a new problem.

In a qualitative investigation, Yackel, Cobb, and Wood (1991) studied a secondgrade classroom in which small-group problem solving followed by whole-class discussion was the primary instructional strategy for the entire school year. They discovered that this method created many learning opportunities that do not typically occur in traditional classrooms. Students were able to resolve conflicting points of views because of the collaborative dialogue that occurred in the small-group settings. They were also able to relate well with their peers because of the constant ongoing dialogues.

Research clearly supports the use of small groups as part of the mathematics classroom. This method can result in increased student learning as measured by traditional assessments as well as other important outcomes such as improvement in student ability to communicate, resolve differences, and get along with each other. Research studies show that small-group instruction should be thought of as an instructional practice that is appropriate for certain learning objectives and as a practice that can work well with other classroom strategies including whole-group instruction.

\section{Use of Technology}

Students come to school from a digital home where they use technology to communicate throughout the world, do research, and create new environments, but when they enter their classrooms, they enter an environment where the primary learning tools are lecture, note taking, and rote learning. Research has shown that the use of computers 
and graphing calculators in the mathematics classroom can have a positive impact on student achievement (Dunham \& Dick, 1994). Tileston (2004) gives the following reasons why technology can be a powerful learning tool:

- Technology is not limited by the classroom walls.

- Technology does not know or care what the student's socioeconomic status may be and thus helps level the playing field for the students.

- Technology provides an equal opportunity for everyone to learn.

- Technology is more in tune with the way our students learn today.

- Technology is so much a part of the real world that to limit its use in the classroom is to limit our students' ability to compete in the world.

Educational researchers have long promoted the increased use of technology in education for the potential benefits it brings to teaching and learning environments. As far back as 1983, VanDeMark (1983) stated, "Teachers must become aware of the problems, potentials, uses, and effectiveness of computers so that they can be applied effectively in education." Awareness of the potential uses of technology was a requirement for its successful use. In 1991, NCTM developed professional standards for teaching mathematics. They concluded that teachers must be aware of the tools necessary to enhance discourse in the mathematics classroom and emphasized that technology was one of those tools.

Many studies have examined how technology can be used to learn mathematics at multiple educational levels (Dugdale, 2001; Jiang \& McClintock, 2000; Lloyd \& Wilson, 2001). These studies have investigated technology and content areas in a way that explicitly addresses the kinds of uses and applications of very specific types of 
educational technology for precise subject areas, grades, and student populations. Results of these studies indicate that different forms of activities performed on the computer are related to different levels and types of thinking which, in turn, are associated with a variety of conclusions. For example, when using the computer for electronic communication and for writing papers, students exhibited higher levels of mathematical literacy, while other activities such as programming and using drawing or painting type software were associated with lower levels of mathematical literacy (Papanastasiou \& Ferdig, 2006).

Hembree and Dessart (1986) conducted a meta-analysis of 79 non-graphing calculator studies and concluded that the use of handheld calculators improved student learning. They also concluded that students' understanding of arithmetical concepts and problem-solving skills improved. In addition, they found that students using calculators tended to have preferential attitudes towards mathematics and much better self-concepts in mathematics than their counterparts who did not use calculators. In fact, there was no loss in student ability to perform paper-and-pencil computational skills when calculators were used as part of mathematics instruction.

Research on the use of graphing calculators has also shown positive effects on student achievement involving graphing ability, conceptual understanding of graphs, and the capacity to relate graphical renderings to other representations such as tables and symbolic images (Wilson \& Krapfl, 1994). Function concepts and spatial visualization are some of the other content areas where improvements have been shown when these calculators have been used in instruction. Studies have also found that students are better problem solvers when using graphing calculators. Additionally, students were more 
flexible in their thinking with regard to solution strategies, had greater perseverance, and focused more on trying to understand the problem conceptually rather than simply focusing on computations. From their research on the use of graphing calculators, Dunham and Dick (1994) concluded that calculators provided more time for instruction, supplied more tools for problem solving, and allowed students to perceive problem solving differently. They believed that classroom observations and interviews suggest that graphing calculators can lead to increased group work, investigations and explorations, and problem solving. Research has shown that their use produces minimal, if any, negative impact on basic skills, factual knowledge, or computational skills. On the whole, studies have found that the use of calculators changes the content, methods, and skill requirements in mathematics classrooms (Wilson \& Krapfl, 1994). In addition, studies have also shown that teachers ask more higher-ordered questions when graphing calculators are present. Wilson and Krapfl conclude that students improve their mathematical performance, understand functions in fundamentally different ways, and improve their disposition toward mathematics.

\section{Emphasizing Understanding and Problem Solving}

Research on the effects of teaching for meaning and understanding in mathematics was employed as far back as the 1940s by William Brownell. L. Fuchs, D. Fuchs, Karns, Hamlett, Katzaroff, and Dutka (1997) have shown that low-performing students do better with a problem-solving focus, because they stay on task and work toward an end they can understand and self-evaluate. Several studies have found that focusing instruction on the meaningful development of important mathematical ideas increases student learning (Carpenter, Franke, \& Jacobs, 1998; Fuson, 1997; Grant, 
Hiebert, \& Wearne, 1998; Murray, Olivier, \& Human, 1998). Studies have consistently shown that an emphasis on teaching for meaning has positive effects on student learning, including better initial comprehension, greater retention, and increased likelihood that the ideas mastered can be applied to new problems. Research has also revealed that an emphasis on teaching for meaning has positive effects on student learning, including better initial comprehension, greater retention, and an increased likelihood that the ideas will be used in new situations. From a longitudinal study, Carpenter, Franke, and Jacobs, (1998) concluded that students develop understanding before mastery of procedures. These positive effects have also been found in studies done in high-poverty areas. In a study by Knapp and Peterson (1995), it was found that when students were taught for meaning, those students not only exhibited the penchant for tackling more complex problems, but they also scored higher on traditional testing. From Aubrey's (1997) investigation into teachers' pedagogical subject knowledge, it was concluded that teachers should emphasize the mathematical meanings of ideas, including how the idea, concept, or skill is connected in multiple ways to other mathematical ideas in a logically consistent and sensible manner.

There is evidence that students can learn new skills and concepts while they are working out solutions to problems (Wearne \& Hiebert, 1988). For example, students with only knowledge of basic addition can extend their learning by developing informal algorithms for addition of larger numbers. Likewise, by solving carefully chosen nonroutine problems, students can develop an understanding of many important mathematical ideas, such as prime numbers and perimeter/area relations. According to Cobb, Wood, and Yackel (1991), it is not necessary for teachers to focus first on skill 
development and then move on to problem solving. Both can be done together. Skills can be developed on an as-needed basis, or their development can be supplemented through the use of technology. Cobb et al. suggest that a problem-centered instructional approach in which the teacher and student engage in discourse that has mathematical meaning can result in better retention for students. In actuality, there is evidence that if students are initially drilled too much on isolated skills, they have a harder time making sense of them later (Pesek \& Kirshner, 2000).

Results of Standards-Based Curricula Implementation

The National Science Foundation (NSF) funded the design of several instructional materials based on NCTM standards. Table 1 shows some of the materials developed at the high school level.

Table 1

Instructional Materials Developed with National Science Foundation Funding

High School

Applications/Reform in Secondary Education (ARISE)

Core-Plus Mathematics Project

Interactive Mathematics Program

Math Connections

Connected Geometry

By 1998 , many of these NSF-funded programs were being widely used across the nation. In fact, there were more than four comprehensive instructional materials created at each level: elementary, middle, and high school. More than 300,000 high school students in the U.S. were studying from mathematics textbooks developed by NSF- 
funded projects (Maurer, 2000). At the elementary and middle school levels, more than 3 million students were using materials developed by the University of Chicago School Mathematics Project (UCSMP). When compared to traditional curricula, standards-based materials had far more problems set in realistic contexts and far fewer exercises requiring only arithmetic or algebraic computation. Furthermore, the use of calculators was increasingly evident in standards-based materials as compared to traditional textbooks. In addition, most standards-based materials were designed for use with heterogeneous grouping while traditional curricula focused on ability grouping or tracking (E. E. Robinson, M. F. Robinson, \& Maceli, 2000).

Results at the High School Level

One of four high school mathematics core curricula funded by the NSF in 1992 was MATH Connections. It was designed as an integrated program to introduce the concepts of higher mathematics to all students. The 3-year curriculum replaced the traditional Algebra I, Geometry, and Algebra II sequence and was designed for 9th-, 10th-, and 11th-grade students. In a study conducted by Leinwand (1996), two different classes of students in one suburban high school were chosen for comparison. One group took Pre-algebra and Algebra in grades 9 and 10; the other group took MATH Connections, Year 1 and Year 2, in grades 9 and 10. For the 26 students in the traditional program and the 30 students in the MATH Connections program, each student score was examined in the fall of 1992 on the grade 8 Connecticut Mastery Test (CMT) and in the spring of 1995 on the grade 10 Connecticut Academic Performance Test (CAPT). Both groups of students had similar mean test scores in grade 8 , but at the end of grade 10 , the MATH Connections students had significantly stronger scores on the CAPT. Further 
findings indicated that MATH Connections students generally scored higher than those in traditional programs on the CAPT, regardless of whether their initial eighth-grade CMT score represented a high or low level of achievement.

Another of the four NSF-funded curricula was the Core-Plus Mathematics program (CPMP) curriculum. CPMP developed student and teacher materials to serve a 3-year high school mathematics curriculum for all students and a fourth-year course for potential college-bound students. The main theme of CPMP is mathematics as sensemaking. Students investigate problems set in real-life contexts within an integrated curriculum that includes algebra and functions, geometry and trigonometry, statistics and probability, and discrete mathematics. A national field-test of Course 1 was conducted during the 1994-1995 school year (Schoen, Hirsch, \& Ziebarth, 1998). A broad, diverse cross section of approximately 5,650 students in 36 high schools in urban, rural, and suburban areas was involved. Analysis of the data, controlled statistically for initial differences, indicated that CPMP students were significantly better at the end of the year regarding the application of reasoning and mathematical concepts than both comparison students in the field-test schools and the standardized test's nationally representative, endof-year 9th-grade norm group.

A third NSF-funded project, the Interactive Mathematics Program (IMP) is a 4year, problem-based mathematics curriculum for secondary-school students that focuses on open-ended explorations of complex problems, yet covers the essential content of the traditional Algebra I-Geometry-Algebra II/Trigonometry-Precalculus sequence. The design of this integrated program began in 1989 and was conceived for non-collegebound as well as college preparatory students to fulfill the mathematics standards 
developed by the NCTM. In a study of high schools with low-income and low-achieving student populations, higher growth in mastery was observed among 9th-grade students enrolled in the IMP courses than for those enrolled in the other curricula, including traditional Algebra I (White, Gamoran, and Smithson, 1995). The IMP students began at a lower level than the other students in college-preparatory courses and finished at a higher level.

\section{Conclusion on Standards-Based Curricula}

The results of studies of standards-based curricula clearly suggest that all students, including Hispanic and African-American at-risk students, can successfully meet the challenges of a mathematically rigorous course at any level. A review of schools in Washington state by O'Day and Bitter (2003) looked at those in need of improvement, comparing those who made progress with those who did not. Findings indicated that a school's ability to develop a coordinated and coherent instructional program was a key factor in its ability to meet and surpass academic growth targets. Problem-oriented, standards-based curricula can help students learn facts and skills as they master more abstract content. If teachers use these standards-based curricula as the courses are intended, students can continue to increase their achievement in mathematics.

Evidence suggests that students fare well with standards-based curricula, and long-term benefits seem more impressive than the short-term benefits. Although the performance gaps between Whites and under-represented minorities and between low and high socioeconomic-status (SES) students have not been eradicated, the gap is far less dramatic than those typical of traditional curricula (Schoenfeld, 2002). Research suggests that when teachers are adequately prepared to help students work through standards- 
based materials, the students learn not only skills and procedures but also concepts and problem solving as well. Moreover, these standards-based curricula appear to represent a significant step toward equitable instruction. An interesting, exciting, real-world curriculum can and does prepare all students mathematically to pursue a higher education.

\section{Carnegie Learning Cognitive Tutor ${ }^{\circledR}$}

In this study, Carnegie Learning's Cognitive Tutor ${ }^{\circledR}$ was chosen as the standardsbased curricula. Cognitive Tutor Algebra I was rated as one of the promising programs by the U.S. Department of Education (DOE) Expert Panel (1999). Carnegie Learning's Cognitive Tutor ${ }^{\circledR}$ instructional strategy relied on both the teacher-led instruction and the use of computers to differentiate instruction for individual students. This allowed all students to be responsible for making sense of the learning at their cognitive level without direct teacher intervention. In addition, the program would help to reduce the teacher's burden of trying to meet the needs of the wide range of skills in each classroom.

\section{Carnegie Learning}

Carnegie Learning is a publisher of core, full-year mathematics programs as well as supplemental intervention applications for middle school, high school, and postsecondary students. Cognitive Tutor ${ }^{\circledR}$ programs provide intelligent software tutoring for each student, combined with text and teacher-led classroom instruction. Carnegie Learning offers curricula for Algebra readiness, Algebra, Geometry, Integrated Math, and state exam preparation. Carnegie Learning's Cognitive Tutors ${ }^{\circledR}$ are based on research regarding how students think, learn, and apply new knowledge in mathematics. The 
Tutors use students' intuitive problem-solving abilities as a powerful bridge to more formal and sophisticated mathematical comprehension.

Immersing and engaging students in mathematical problem solving are the core goals of Carnegie Learning's Cognitive Tutors ${ }^{\circledR}$. The program is a computer-enhanced, interactive learning course that is designed to teach students both in the classroom and in personalized computer sessions. The design of the program includes students spending 3 days per week in a classroom setting and 2 days per week in a computer lab, interacting with the course software. The Carnegie software is designed to offer individualized assistance to students, allowing them to progress at their own pace. Students using the software receive immediate feedback, providing real-time tutoring. The software is designed to understand methods that a student may use to solve a problem and provides individualized levels of help. It paces the curriculum based on each student's comprehension and ability. Student progress is displayed on individual computer screens during the lab.

A theory of cognition adopted by the Adaptive Control of Thought (ACT), later reclassified as ACT-R (Rational) was part of John Anderson's work in the psychology and computer science departments at Carnegie Mellon University that led to Carnegie Learning's Cognitive Tutors ${ }^{\circledR}$ development. Newell (1990) defines ACT-R as a Unified Theory of Cognition that aims to explain the full range of human intellect. ACT-R was put into practice as a computer program, which had the benefit of requiring the theory to be precise about all of its claims. Anderson (2002) had used ACT-R with great success to model laboratory results in learning, memory, and problem-solving and was challenged to show that the same basic approach could explain cognition outside of a laboratory 
environment. The aim of an ACT-R model is to predict behavior as its applies to psychological laboratory studies. The model needs to correctly represent human knowledge in order to predict behavior, and it must also understand how that knowledge results in particular conduct. As it is applied to education, the model of knowledge results in expectations about what students can and cannot do as well as predictions about what activities and experiences will help students learn to achieve curricular goals.

In addition to the design of mathematical tasks, the ACT-R theory guides instruction in the Cognitive Tutor ${ }^{\circledR}$, because the software includes an active cognitive model which is similar to an ACT-R model within the software (Corbett, Koedinger, \& Anderson, 1997). This ACT-R model has two purposes. First, the model attempts to determine the particular student's strategy in solving a problem by following student actions. The method by which it does this is called model tracing. Second, all the student action is associated with one or more skills which are associated with the knowledge components in the cognitive model. Individual students' performance is tracked over time and displayed to students through a "skillometer." The computer skill profile offers students the opportunity to engage in curriculum problems that focus on the skills about which the student is weakest (Corbett \& Anderson, 1995). In addition, the skill model is used to implement mastery learning. The student can only move on to the next section of curriculum when all skills in a section of the curriculum are determined to be sufficiently mastered. Only then will the computer introduce new skills.

\section{Cognitive Tutor ${ }^{\circledR}$ Algebra I}

The Cognitive Tutor ${ }^{\circledR}$ emphasizes standards-based reform strategies such as the use of verbal, numerical, algebraic, and graphical representations to solve problems, and 
every problem in the Cognitive Tutor ${ }^{\circledR}$ curriculum consists of one or more of the following tools, which make use of this approach:

- The Scenario presents a written description of a real-world problem and poses several questions. These authentic situations motivate and engage students and help them formulate mathematical concepts.

- Students answer many scenario questions using the Worksheet, allowing them to represent the problem, using numbers and text. Students must describe the quantities found in the problem scenario and identify the unit of measure. Filling in the worksheet helps them recognize mathematical patterns.

- Students represent the problem pictorially using the Grapher. They must identify bounds and intervals, label axes, plot points, and draw lines or curves.

- $\quad$ Students use the Solver to answer questions using algebraic representations. They must identify the steps used to solve each equation or simplify each expression.

- The Skillometer visually summarizes students' mastery of math skills. After each problem, these skills are evaluated and students are given new problems that target deficient skills, providing completely individualized instruction.

- Geometric problems are represented visually in the Diagram. Using this tool, students are able to label angle measures and side lengths.

- The Glossary contains formal mathematical terms. Students are able to search for and view definitions and worked examples. 
- Additional support tools in some problems include the ratio, transformation, and reason tools.

In studies of the Algebra I Cognitive Tutor ${ }^{\circledR}$ conducted in Pittsburgh and Milwaukee (Koedinger, Anderson, Hadley, \& Mark, 1997), students were tested on the standardized exams, Scholastic Aptitude Test (SAT) and Iowa Test of Basic Skills, as well as on performance-based problem solving. Cognitive Tutor ${ }^{\circledR}$ students significantly outscored their peers on the standardized tests (by about 0.3 standard deviations), but the difference in performance was particularly pronounced on tests of problem solving and multiple representations where the Cognitive Tutor ${ }^{\circledR}$ students outscored their peers by $85 \%$, representing effect sizes from 0.7 to 1.2 standard deviations. In Moore, Oklahoma, a study was conducted where teachers were asked to instruct some of their student classes using Cognitive Tutor ${ }^{\circledR}$ and some using the textbook they had been previously using (Morgan \& Ritter, 2002; National Research Council, 2003). The study found that Cognitive Tutor ${ }^{\circledR}$ students scored higher on a standardized test (the Educational Testing Service [ETS] Algebra I End-of-Course exam), received higher grades, reported more confidence in their mathematical abilities, and were more likely to believe that mathematics would be useful to them outside of school. This study was recognized by the U.S. DOE's What Works Clearinghouse as having met the highest standards of evidence. It showed effect sizes of approximately 0.4 standard deviations.

Cognitive Tutor ${ }^{\circledR}$ Geometry

The Cognitive Tutor ${ }^{\circledR}$ Geometry uses collaborative classroom exercises, software sessions, and innovative problem solving to help students develop the skills and knowledge needed to progress from concrete to abstract thinking. Its connections to 
Algebra advance student learning by building on prior knowledge. Early evaluations of Cognitive Tutor Geometry showed great promise, with effect sizes of approximately one standard deviation (Anderson, Corbett, Koedinger, \& Pelletier, 1995).

\section{Dissenting Voices to Standards-based Practices}

Not everyone agrees with the standards-based reform movement in mathematics. Detractors suggest that the recent "reform" efforts contribute to the fact that U.S. students' math performance is seriously lagging most countries in the world. They purport that the reform leads to less and less exposure to rigorous, content-rich mathematics. They also contend that reformers speak of higher-order thinking, conceptual understanding and solving problems, but neglect the systematic mastery of the fundamental building blocks necessary for success in any of these areas. Detractors go on to suggest that reformers focus on things like calculators, blocks, guesswork, and group activities but they shun things like algorithms and repeated practice. Detractors claim that standards-based reform movements are shy on fundamentals and they also lack the mathematical depth and rigor that promotes greater achievement (Schoenfeld, 2004).

Detractors also argue that standards-based mathematics curricula do not have a research base of student mathematical performance to support their use (Marshall, 2003). However, that implies that traditional programs, which still make up the vast majority of the mathematics programs in use, have an excellent record of achievement in promoting mathematics learning. In addition, it disregards decades of poor performance documented by the National Assessment of Educational Progress (NAEP) and by three international assessments, the latest being the Third International Mathematics and Science Study Repeat (TIMSS-R). Besides, the lack of knowledge and understanding of mathematics 
discussed by Liping Ma in her book [Knowing and Teaching Elementary Mathematics, 1999] is the by-product of mathematics programs that were in place long before standards-based mathematics curricula existed.

By demanding research to document the effectiveness of reform curricula, detractors are either unaware of the history of student performance using the traditional curricula or are choosing to ignore more than 30 years of widely reported results. In reality, Hiebert (1999) believes that detractors are ignoring the largest database of mathematics achievement when they presume that traditional mathematics programs have shown themselves to be successful. All the evidence indicates that the traditional curriculum and instructional methods in the United States are not serving our students well.

\section{Summary}

Based on the review of the literature, the predominant form of instruction in our nation's schools has been unsuccessful in promoting conceptual understanding and application of mathematics to real-life contexts. In fact, it may be one of the root causes for low-performing students. To many students, school mathematics is an endless sequence of memorizing and forgetting facts and procedures that make little sense to them. The current standards-based reform movement emphasizes students being actively involved in their study of mathematics and encourages them to see the big picture. Current data suggest that most classroom instruction is geared toward the development of rote procedural skills. Existing methods of teaching do not develop the high levels of conceptual understanding or the reasoning, problem solving, and communication skills that students will need to be competitive. Although some research has been done that 
suggest that standards-based programs are suspect, most of these studies have not been able to attribute causality to the reform programs (Steen, 2002). The literature clearly highlights the need to investigate standards-based curricula and practices in order to identify key instructional strategies that can improve the academic achievement of lowperforming students. 


\section{CHAPTER III}

\section{METHODS}

This study aimed to investigate whether standards-based reform initiatives in Miami-Dade County Public Schools (M-DCPS) mathematics classrooms could improve low-performing student achievement (categorized as Level 1 and Level 2 status on the state's mathematics assessment) and close the achievement gap between disadvantaged and minority students and their peers. This chapter provides (a) an overview of the research design, (b) a description of the population and samples, (c) a description of the instrumentation and variables, and (d) the procedures and statistical analysis used to answer the research questions.

\section{Research Design}

There are three broad types of experimental design identified by Cook and Campbell (1979): pre-experimental, true experimental, and quasi-experimental. In a true experimental design, subjects can be randomly assigned to groups in a natural manner. This offers the best control for selection bias. However, in K-12 education, this kind of design is rarely possible. The next best thing when random assignment is not possible is a pretest-posttest nonequivalent control-group design which uses intact groups. However, threats to validity need to be carefully controlled in this design. According to Cook and Campbell, both true experimental and quasi-experimental designs are far superior for establishing causal relationships than are pre-experimental designs. This study involved high school students and teachers and followed a quasi-experimental (nonrandomized) design. 
At the time of this study, M-DCPS was the largest district in Florida and the fourth largest district in the country. According to the statistics provided by the district, M-DCPS had 367 schools with more than 360,000 students and over 21,000 teachers. The ethnic composition of the student population was $9.6 \%$ White Non-Hispanic, $27.6 \%$ Black Non-Hispanic, $60.4 \%$ Hispanic, and $2.4 \%$ other ethnic groups. There were a total of 35,929 ninth-grade students and 43,658 tenth-grade students in the district (M-DCPS, 2006).

\section{Sample Population}

The sample population was derived from 9th- and 10th-grade students at two urban high schools of similar demographics in the district. The treatment group was comprised of algebra and geometry teachers and their students. Algebra teachers taught 9 th-grade students and the geometry teachers taught 10 th-grade students. The experimental group was derived from a school that had 2,424 students enrolled. The ethnic composition of the student population was 1\% White Non-Hispanic, 94\% Black Non-Hispanic, $4 \%$ Hispanic, and $1 \%$ other ethnic groups. There were a total of 757 ninthgrade students and 750 tenth-grade students in the school. The final 9th-grade research sample consisted of 238 students and 8 teachers and the 10th-grade sample consisted of 150 students and 5 teachers.

The group used for comparison consisted of algebra and geometry teachers and their students. As with the treatment group, algebra teachers instructed 9th-grade students and the geometry teachers instructed 10th-grade students. The control group was derived from a school that had 2,791 students enrolled. The ethnic composition of the student 
population was $1 \%$ White Non-Hispanic, $86 \%$ Black Non-Hispanic, $13 \%$ Hispanic, and less than $1 \%$ other ethnic groups. There were a total of 906 ninth-grade students and 696 tenth-grade students in the school. The final 9th-grade research sample consisted of 223 students and 8 teachers and the 10th-grade sample consisted of 275 students and 6 teachers.

\section{Instruments and Variables}

One of the primary instruments used in this study was the district mathematics interim assessment developed by Educational Testing Service (ETS). The interim assessment was designed to help classroom teachers monitor their students' achievement of the curriculum benchmarks outlined in Florida's Sunshine State Standards in Reading and Mathematics. The purpose of these interims was to provide educators with meaningful and timely information about the academic achievement and needs of every student. The results of the first two interim assessments administered in October and January were obtained.

The Kuder-Richardson 20 reliability value for the district's mathematics interim assessments was greater than 0.80 . The Kuder-Richardson 20 (KR-20) reliability formula measures the internal consistency of test items. A high value indicates that test items tend to measure the same skills, because students who get one answer correct are likely to get another correct as well. KR-20 usually varies between 0 and 1 . On an assessment that covers a single, focused topic area, a reliability value of 0.6 to 0.65 is considered acceptable for group prediction. For individual prediction, a value of 0.8 or above is considered acceptable. An assessment with reliability in excess of 0.80 is usually considered very reliable (MacLennan, 1993). 
To ensure content validity the district's mathematics interim assessments contained at least four items for each tested benchmark of the state's Sunshine State Standards. In addition, MDCPS teachers and curriculum specialists rigorously reviewed the assessments to ensure that they complied with district requirements and followed the district's curriculum pacing guides.

The Classroom Observation Protocol (COP; Appendix A) was used to gather information on teaching practices of both the experimental and comparison groups (Love, 2002). It uses a Likert scale to measure the degree to which a set of teaching practices are evident in a classroom where standards-based mathematics is being taught (higher-order thinking, cooperative learning groups, classroom discourse, and alternative assessment).

For two years (2006 and 2007), the FCAT Development Scale Score (DSS) was obtained from the district's Student Performance Indicator (SPI) data warehouse. This was used to determine if students in the comparison group had made significantly higher yearly growth than students in the comparison group. The DSS was created to help parents and others understand students' year-to-year progress. It ranges from 0 to about 3000. Students should receive higher scores as they move from grade to grade, based upon their increased achievement.

Demographic variables collected on students included race/ethnicity, gender, and free-or-reduced lunch - all of which were used to determine socioeconomic status. Academic variables collected included students' Florida Comprehensive Assessment Test (FCAT) achievement level, their DSS for 2 years, and whether they were categorized as having limited English proficiency (LEP). 


\section{Procedures}

\section{Selection of the Schools}

For the selection of the schools involved in this study, similar schools were compared to one another based on a combination of demographic factors that included the school-wide percentages of low-income students, the school enrollments, and several ethnicity percentages. The letter-grade performance of the schools over a 4-year period was also included in the selection process.

The treatment in this study was conducted over an 18 -week period. Teachers in the experimental group received professional development regarding the use of new curricula for Algebra (Cognitive Tutor ${ }^{\circledR}$, Algebra I) and Geometry (Cognitive Tutor ${ }^{\circledR}$, Geometry) and the use of standards-based practices prior to the beginning of the school year, while teachers in the control school received no treatment, but served as a comparison group. Prior to the start of school in August, the experimental group received a multi-day inservice on the use of the new curricula and standards-based practices. On the first day, teachers were introduced to the tenets of standards-based reform founded by some of the research done by Marzano (2003) that included: (a) beginning and closing lessons, (b) questioning for understanding, (c) advanced organizers and note taking, (d) cooperative groups, and (e) differentiated instruction. Two days were employed to introduce the teachers to the philosophy of the Cognitive Tutor ${ }^{\circledR}$ curricula. Teachers learned how students would be expected to transition between the use of the computer twice per week and the teacher- led classroom instruction three times per week. They also learned how to facilitate the computer lab time while keeping each student actively 
engaged. In addition, teachers learned to read the computer-generated reports and how to use them to differentiate the instruction for individual students.

Three full-day follow-up sessions were held on Saturdays in the month of October and December to assist with implementation of the new curricula and reinforcement of standards-based practices, including cooperative learning groups and use of manipulatives and technology (Cognitive Tutor ${ }^{\circledR}$ Labs for Algebra and Geometry) over the remainder of the study. During the Saturday sessions, teachers shared their practices and challenges and worked to clarify their roles with the new curricula. No subsequent sessions were held due to other constraints on teachers' professional development obligations.

At the end of each 9-week period, students from grades 3 through 10 were assessed in reading and mathematics by the district, using interim assessments developed by ETS. All testing results were uploaded to a secure central database (Edusoft) and made available to individual teachers and their principals. Through the district's central database for analysis, results from the district's first and second interim mathematics assessments were obtained for all 9th- and 10th-grade students in both the experimental and comparison groups.

Teachers in the experimental and comparison groups were observed using the COP. The observations were conducted with the COP by the mathematics coaches at each school. The coaches met and agreed upon what the standards would be and how they would use the Likert scale COP based upon their observations. The observations occurred at least once a week (as the school schedule permitted) and lasted for an entire class period as teachers worked with all students throughout the study. The first set of 
observations began close to the end of the first 9-week period to give the teachers time to become familiar with the new curricula. Subsequent observations were done during the second nine-week period as the school calendar permitted. Each teacher was observed at least three times over the 18 -week period.

\section{Statistical Analysis}

To determine if standards-based curricula or practices on the part of mathematics teachers increased the achievement of low-performing students, each grade was analyzed separately. One data set included 9th-grade, low-performing students studying Algebra, while the other data set included 10th-grade, low-performing students studying Geometry. Therefore, each analysis was conducted twice, one for each grade level. These two analyses involved cross-tabulations with chi-square tests that explored preliminary descriptive analysis conducted on the variables gender, FCAT level, LEP, and socioeconomic status (SES) involving free and reduced-price lunch.

To determine if students taught by teachers that implement standards-based curricula and practices made significantly higher gains than students taught by teachers using traditional curricula and practices, analyses of covariance (ANCOVAs) were conducted. For the experimental and comparison group, the students' mean test scores on the district's second interim mathematics assessment were compared in the ANCOVA. Students' test scores on the district's first interim mathematics assessment were used as a covariate as well as issues involving gender, LEP, and SES. ANCOVAs were used because these models can help reduce residual variation (Agresti, 1996).

To determine if students in the experimental group made significant yearly growth over the comparison group, the measurement difference between their 2006 and 
2007 DSS was calculated. An ANCOVA was conducted to see if there were statistically different DSS changes.

For each analysis of covariance, three models were fit and tested. First a statistical model was explored to determine if the slopes of all the covariates of the treatment by background variables were zero. If not rejected, then the slopes of the covariates were tested for equality. If this was not rejected, then the ANCOVA model with the one covariate (either the first interim assessment or 2006 DSS) was fit and the adjusted means were tested for differences between groups and the student background variables. If the equal slopes hypothesis was rejected, then the ANCOVA model with unequal slopes was fit, and adjusted means were compared at three levels of the covariate-at the 25 th percentile, at the median, and at the 75 th percentile. All of these models contained twoway interaction terms between group, FCAT level, gender, SES, and LEP. For significant interactions, pair-wise comparisons of means were carried out using Holm's sequential Bonferroni procedure. The level of significance for each test was $p<.05$. SPSS (v.16) was used for analysis.

\section{Summary}

This study investigated the relation between standards-based teaching practices, standards-based curricula, and student achievement in mathematics. The data sets included 461 ninth-grade students studying Algebra and 423 tenth-grade students studying Geometry in two urban high schools with similar demographics. Data were collected from two online sources-Edusoft testing program and the district's SPI. The primary statistical analyses involved covariance of the students' mathematics scores on the district's interim assessment, administered at the end of the second 9-week period, 
and the change in students' FCAT DSS between the years 2006 and 2007. Independent samples t-tests were conducted on the Classroom Observation Protocol (COP) scores. 


\section{CHAPTER IV}

\section{RESULTS}

This chapter presents the results of the statistical analyses that were used to answer the research questions. It includes descriptive statistics (frequencies, percentages, means, and standard deviations), chi-square tests, and analyses of covariance (ANCOVAs), and $t$-tests. Two data sets were created for the analyses. The first data set contained the experimental and the comparison 9th-grade algebra students, their Florida Comprehensive Assessment Test (FCAT) levels, their test scores on the two district mathematics interim assessments, their socioeconomic status (SES), their Limited English Proficiency status (LEP), their gender and ethnicity, their FCAT Developmental Scale Score (DSS) for 2006 and 2007, the differences in their DSS scores over the two years, their teachers, and the observation scores for each teacher on the Classroom Observation Protocol (COP) instrument.

The second data set included the experimental and the comparison 10th-grade geometry students, their FCAT levels, their test scores on the two district mathematics interim assessments, their SES and LEP status, their gender and ethnicity, their FCAT DSS for 2006 and 2007, the differences in their DSS scores over the two years, their teachers, and the observation scores for each teacher on the COP instrument.

\section{Demographics of the Groups}

The purpose of the first analysis was to describe the demographic characteristics of the students in the experimental and comparison group and to determine if the two groups differed with regard to ethnicity, gender, LEP, and socio-economic status (SES). Cross tabulations with chi-square tests were conducted to evaluate differences. 
Demographic data shown in Tables 2 and 3 presents the ethnicity, gender, and

SES status by grade levels.

Table 2

Demographic Distribution of Ninth-Grade Algebra Students $(N=461)$

\begin{tabular}{|c|c|c|c|c|}
\hline \multirow[b]{2}{*}{ Variable } & \multicolumn{2}{|c|}{$\begin{array}{l}\text { Experimental group } \\
\qquad(n=238)\end{array}$} & \multicolumn{2}{|c|}{$\begin{array}{c}\text { Comparison group } \\
\qquad(n=223)\end{array}$} \\
\hline & $f^{\mathrm{a}}$ & $\%$ & $f^{\mathrm{a}}$ & $\%$ \\
\hline \multicolumn{5}{|l|}{ Ethnicity } \\
\hline $\begin{array}{l}\text { American Indian/ } \\
\text { Alaskan Native }\end{array}$ & 0 & 0.0 & 0 & 0.0 \\
\hline Asian & 0 & 0.0 & 0 & 0.0 \\
\hline African American & 225 & 94.5 & 210 & 94.2 \\
\hline Hispanic & 10 & 4.4 & 13 & 5.8 \\
\hline Multiracial/Ethnic & 1 & 0.4 & 0 & 0.0 \\
\hline White & 2 & 0.8 & 0 & 0.0 \\
\hline \multicolumn{5}{|l|}{ Gender } \\
\hline Female & 238 & 51.6 & 223 & 48.4 \\
\hline Male & 107 & 47.8 & 117 & 52.2 \\
\hline \multicolumn{5}{|c|}{ Limited English proficient } \\
\hline Yes & 33 & 13.9 & 17 & 7.6 \\
\hline No & 205 & 86.1 & 206 & 92.4 \\
\hline \multicolumn{5}{|l|}{ Socioeconomic status } \\
\hline Free/reduced lunch & 120 & 50.4 & 155 & 69.5 \\
\hline Paid lunch & 118 & 49.6 & 68 & 30.5 \\
\hline
\end{tabular}

${ }^{\mathrm{a}} f=$ Frequency 
Table 3

Demographic Distribution of Tenth-Grade Geometry Students $(N=423)$

\begin{tabular}{|c|c|c|c|c|}
\hline \multirow[b]{2}{*}{ Variable } & \multicolumn{2}{|c|}{$\begin{array}{l}\text { Experimental group } \\
\qquad(n=150)\end{array}$} & \multicolumn{2}{|c|}{$\begin{array}{l}\text { Comparison group } \\
\qquad(n=273)\end{array}$} \\
\hline & $f^{\mathrm{a}}$ & $\%$ & $f^{\mathrm{a}}$ & $\%$ \\
\hline \multicolumn{5}{|l|}{ Ethnicity } \\
\hline $\begin{array}{l}\text { American Indian/ } \\
\text { Alaskan Native }\end{array}$ & 1 & 0.7 & 0 & 0.0 \\
\hline Asian & 0 & 0.0 & 1 & 0.4 \\
\hline African American & 144 & 96.0 & 241 & 88.3 \\
\hline Hispanic & 4 & 2.7 & 30 & 11.0 \\
\hline Multiracial/Ethnic & 1 & 0.7 & 0 & 0.0 \\
\hline White & 0 & 0.0 & 1 & 0.4 \\
\hline \multicolumn{5}{|l|}{ Gender } \\
\hline Female & 72 & 48.0 & 125 & 45.8 \\
\hline Male & 78 & 52.0 & 148 & 54.2 \\
\hline \multicolumn{5}{|c|}{ Limited English proficient } \\
\hline Yes & 22 & 14.7 & 27 & 9.9 \\
\hline No & 128 & 85.3 & 246 & 90.1 \\
\hline \multicolumn{5}{|l|}{ Socioeconomic status } \\
\hline Free/reduced lunch & 74 & 50.7 & 189 & 69.2 \\
\hline Paid lunch & 76 & 49.3 & 84 & 30.8 \\
\hline
\end{tabular}

${ }^{\mathrm{a}} f=$ Frequency

The sample consisted of 273 Level 1 and 188 Level 2 ninth-grade students and 209 Level 1 and 214 Level 2 tenth-grade students. Ninth-grade students in experimental and comparison groups were predominantly African-American (95\% and 94\% respectively), $\chi^{2}(3, N=461)=3.42, p=.331$. The 10 th-grade experimental and 
comparison group were also largely African-American ( $96 \%$ and $88 \%$ respectively), but there was a significant difference in ethnicities, $\chi^{2}(5, N=423)=13.72, p=.018$. However, Cramer's $V=.18$, which is an index of effect size, indicated that the ethnic differences were relatively small (Agresti, 1996).

With respect to gender, there were no significant differences between students in the experimental or comparison group. Chi-square analyses revealed that within the 9thgrade experimental and comparison groups, there were $52 \%$ and $48 \%$ females respectively, $\chi^{2}(1, N=461)=2.60, p=.107$. Within the 10th-grade experimental and control groups there were $48 \%$ and $46 \%$ respectively, $\chi^{2}(1, N=423)=0.19, p=.663$.

With respect to LEP status, chi-square analyses revealed that the 9th-grade experimental group (14\%) had a significantly larger population of LEP students than the comparison group $(8 \%), \chi^{2}(1, N=461)=4.64, p=.031$. While there were significant differences between the two groups, Cramer's $V=.10$ indicated that the differences were relatively small. There was no significant difference between the percentages of LEP students in the 10th-grade experimental and control groups, $\chi^{2}(1, N=423)=2.16, p=$ .142 .

With respect to SES status, chi-square analyses revealed that the 9th-grade comparison group (70\%) had a significantly larger percentage of students applying for free or reduced lunch than the experimental group $(50 \%), \chi^{2}(1, N=461)=17.43$, $p<.001$. Similarly, in the 10th-grade comparison group, $69 \%$ of the students applied in comparison to $51 \%$ percent of the experimental group, $\chi^{2}(1, N=423)=16.30, p<.001$. While there were significant differences between the two groups at both grade levels, 
Cramer's $V=.19$ for both 9th- and 10th-grade groups indicated that the differences were relatively small.

\section{Analyses of Achievement}

\section{Research Question 1}

Is there a significant difference between the mathematics scores as measured by the district's second interim assessment of students taught by teachers using standards-based curriculum and students taught by teachers using a traditional curriculum?

To answer Research Question 1, analyses of covariance were conducted to measure the differences between experimental and comparison groups' test scores on the district's second interim mathematics assessment as a function of student background variables (group, gender, LEP, and SES) with test scores on the district's first interim mathematics assessment as a covariate.

$9^{\text {th }}$ Grade

For the 9th-grade, the homogeneity of slopes hypothesis, that the first interim mathematics assessment did not differ by group in predicting the second interim mathematics assessment, was upheld, $F(1,443)=1.34, p=.248$. In the final model, the first interim mathematics assessment was a significant predictor of the second, $F(1,444)$ $=10.04, p=.002$. Table 4 shows the adjusted means for both groups. The experimental groups' adjusted mean for the second interim mathematics assessment $(M=12.91)$ was significantly lower than the comparison groups' mean (adj $M=14.9), F(1,444)=6.76$, $p=.010$. This was an unanticipated result. 
Table 4

Adjusted Means and Standard Errors for Ninth-Grade Students' Second Interim

Mathematics Assessment

\begin{tabular}{lccc}
\hline Group & $n$ & Adj $M^{*}$ & $S E$ \\
\hline Experimental Group & 238 & 12.91 & 0.47 \\
Comparison Group & 223 & 14.90 & 0.67 \\
${ }^{*} p<.05$ & & &
\end{tabular}

There was also a main effect of FCAT Level, $F(1,444)=5.21, p=.023$, with the students in Level 2 having a second interim mathematics assessment adjusted mean $(M=14.84)$ significantly higher than the students in Level $1(\operatorname{adj} M=12.97)$. However, this was moderated by the significant FCAT Level by SES interaction, $F(1,444)=4.79$, $p=.029$. Holm's sequential Bonferroni pair-wise comparisons procedure at $p<.05$ indicated that the FCAT Level 2 students who were in the paid/not-applied-for lunchstatus group scored significantly higher (adj $M=15.70)$ than the FCAT Level 1 students in the paid/not-applied-for lunch-status group ( $\operatorname{adj} M=12.83), p<.004$. In the free/reduced lunch-status groups, there was not a significant difference between FCAT Level $2(\operatorname{adj} M=13.98)$ and Level $1(\operatorname{adj} M=13.11)$ students. $10^{\text {th }}$ Grade

For the 10th-grade, the homogeneity of slopes hypothesis, that the first interim mathematics assessment did not differ by group in predicting the second interim mathematics assessment, was upheld, $F(1,404)=0.21, p=.641$. However, the first 
interim mathematics assessment did differ as a predictor for the two SES groups, $F(1,404)=5.90, p=.016$, so this effect was included in the final model.

In that final model, the first interim mathematics assessment was a significant predictor of the second, $F(1,405)=7.08, p=.008$. Table 5 shows the adjusted means for both groups. The experimental groups' adjusted mean for the second interim mathematics assessment $(M=15.5)$ was significantly higher than the comparison groups' mean (adj $\mathrm{M}=13.1), F(1,405)=11.30, p=.001$.

Table 5

Adjusted Means and Standard Errors for Tenth-Grade Students' Second Interim Mathematics Assessment

\begin{tabular}{lccc}
\hline Group & $n$ & Adj $M^{*}$ & $S E$ \\
\hline Experimental Group & 150 & 15.50 & 0.56 \\
Comparison Group & 273 & 13.06 & 0.51 \\
\hline${ }^{*} p<.05$ & & &
\end{tabular}

There was also a main effect of FCAT level, $F(1,405)=19.63, p<.001$, with the students in Level 2 having a second interim mathematics assessment adjusted mean $(M=15.93)$ significantly higher than the students in Level 1 (adj $M=12.63)$. This was moderated by the significant FCAT Level by LEP interaction, $F(1,405)=6.43, p=.012$. Holm's sequential Bonferroni comparisons indicated that in both the LEP and non-LEP student groups, FCAT Level 2 students scored significantly higher (adj M non-LEP = 15.08 , adj $\mathrm{M} \mathrm{LEP}=16.77)$ than FCAT Level 1 students $(\operatorname{adj} \mathrm{M}$ non-LEP $=13.63$, adj $\mathrm{M}$ LEP $=11.64), p=.004,<.001$, respectively. However, the increase of FCAT Level 2 
students over FCAT Level 1 students was significantly larger for the LEP students than the non-LEP students. There was also a main effect of gender, $F(1,405)=6.53, p=.011$, with females scoring higher (adj $M=15.21)$ than males (adj $M=13.34)$ on the second interim assessment.

The first interim mathematics assessment differed as a predictor for the two SES groups, $F(1,405)=5.71, p=.017$. The slope for the paid/not-applied-for lunch group was $\mathrm{B}=0.17,95 \% \mathrm{CI}(0.06,0.28)$, indicating that an increase in one point on the first interim mathematics assessment resulted in a 0.17 point average increase on the second mathematics assessment. However, the slope for the free/reduced lunch group was .01, $95 \% \mathrm{CI}(-0.06,0.80)$, indicating that the first assessment did not significantly predict the second for this group, $F(1,405)=0.06, p=.806$.

\section{Research Question 2}

Is there a significant difference between the yearly growth in mathematics as measured by the FCAT DSS of students taught by teachers using standards-based curriculum and students taught by teachers using a traditional curriculum?

To answer Research Question 2, analyses of covariance were conducted to measure the differences between experimental and comparison groups on their FCAT DSS growth as a function of student background variables (group, gender, SES, LEP) with their 2006 DSS as a covariate.

$9^{\text {th }}$ Grade

For the 9th-grade, the homogeneity of slopes hypothesis, that the 2006 DSS did not differ by group in predicting the 2007 DSS growth, was upheld, $F(1,447)=0.12$, $\mathrm{p}=.727$. In the final model, the 2006 DSS was a significant predictor of growth, $F(1,448)=74.64, \mathrm{p}<.001$. Table 6 shows the adjusted means and standard errors for 
both groups. Although the experimental groups' adjusted mean for the 2007 DSS growth (adj $\mathrm{M}=89.92$ ) was numerically higher than the comparison groups' mean (adj $\mathrm{M}=$ $69.63)$, the difference was not significant, $F(1,444)=.90, p=.344$. There was a main effect for SES, F $(1,448)=9.68, p=.002$, moderated by a significant interaction between SES and the 2006 DSS, F $(1,448)=9.82, p=.002$. However, students receiving free or reduced lunch had a 2007 DSS adjusted growth mean $(M=82.8)$ which was not significantly different from that of students not receiving free or reduced lunch $(\operatorname{adj} M=$ 76.7), when evaluating growth at the mean 2006 DSS $(M=1682)$. Additional analyses were conducted at the various quartiles to see if the students receiving free or reduced lunch 2007 DSS growth which was significantly different than that of students not receiving free or reduced lunch. The analyses revealed that there were no significant differences at the mean, the 25th- or 75th- percentile for the ninth-grade SES groups. Table 6 Adjusted Means and Standard Errors for Ninth-Grade Students' 2007 Developmental Scale Score Growth $(N=461)$

\begin{tabular}{lccc}
\hline Group & $n$ & Adj $M$ & $S E$ \\
\hline Experimental Group & 238 & 89.92 & 17.62 \\
Comparison Group & 223 & 69.63 & 12.53 \\
\hline
\end{tabular}

$10^{\text {th }}$ Grade

For the tenth-grade analyses, the homogeneity of slopes hypothesis, that the 2006 DSS did not differ by group in predicting the 2007 DSS growth, was not upheld, 
$F(1,410)=4.49, \mathrm{p}=.035$. The 2006 DSS was a significant covariate for predicting the 2007 DSS growth, $F(1,410)=74.13, \mathrm{p}<.001$. The ANCOVA showed a significant main effect for group, $F(1,410)=5.85, \mathrm{p}=.013$. The experimental group mean $(\operatorname{adj} \mathrm{M}=$ 102.3) was significantly higher than the comparison group (adj $M=46.9$ ), when evaluated at the 2006 DSS mean $(M=1746), p=.024$. Table 7 shows the adjusted means and standard errors for both groups.

Table 7

Adjusted Means and Standard Errors for Tenth-Grade Students' 2007 Developmental Scale Score Growth $(N=423)$

\begin{tabular}{lccc}
\hline Group & $n$ & Adj $M^{*}$ & $S E$ \\
\hline Experimental Group & 150 & 102.25 & 18.71 \\
Comparison Group & 273 & 46.89 & 17.13 \\
\hline${ }^{*} p<.05$ when evaluated at 2006 mean DSS $=1746$ & &
\end{tabular}

Analyses were conducted at the various quartiles of 2006 DSS to see if the experimental group 2007 DSS growth was significantly higher than the comparison group at these points. At the 25th-percentile, the 2007 DSS growth for the experimental group (adj $M=133.6$ ) was significantly higher than the comparison group (adj $M=$ $65.9), p=.006$. However, at the median and 75th-percentile, the 2007 DSS growth means for the experimental group (adj $M=78.8$, adj $M=42.4$ ) were not significantly higher than the comparison group $(\operatorname{adj} \mathrm{M}=32.7$, adj $\mathrm{M}=10.7, \mathrm{p}=.070, \mathrm{p}=.258$, respectively). 
To ascertain if the use of technology had an impact on the experimental group, a simple frequency table was run to look at the student usage of the computer portion of the curricula. Table 8 shows the distributions of students for both grade levels. Students in the experimental group were divided into two categories: (a) students who rarely used the computer portion of the curricula; and (b) students who frequently used the computer portion of the curricula. Frequency of use was determined by the computer-generated student reports provided by the program. These reports indicated when each student logged on and the number of units successfully completed by each student.

Table 8

Frequency of Computer Use for Experimental Group in Grades 9 and 10

\begin{tabular}{cccccc}
\hline & \multicolumn{3}{c}{ Rarely used } & \multicolumn{2}{c}{ Frequently used } \\
Grade & $n$ & $f$ & $\%$ & $f$ & $\%$ \\
\hline 9 & 238 & 139 & 58.4 & 99 & 41.6 \\
10 & 150 & 2 & 1.3 & 148 & 98.7 \\
\hline$f=$ Frequency & & & & &
\end{tabular}

An ANCOVA was conducted using the 2007 DSS growth as the dependent variable by computer use (rarely, frequently). In the final model, the grade 9 analysis showed no significant main effect for computer use, $F(1,225)=.50, \mathrm{p}=.482$. The mean DSS growth for the 9th-grade students who used computers frequently was 97.46 ( $\mathrm{SE}=$ 17.37), and the mean growth for students who rarely used computers was 79.67 ( $\mathrm{SE}=$ 17.89). All grade 10 students, except two, used the computer frequently. 


\section{Research Question 3}

Is there a significant difference between the teaching practices as measured by the $\mathrm{COP}$ of teachers using a standards-based curriculum and teachers using a traditional curriculum?

To answer Research Question 3, independent samples $t$-tests were conducted on the COP scores for each of the four constructs (Appendix B) involving 9th- and 10thgrade teachers in the experimental and comparison groups to determine if there were any significant differences between their teaching practices. For the four constructs of the $\mathrm{COP}$, the teaching practices were not significantly different between experimental and comparison groups in either grade.

Classroom Observation Protocol (COP) for 9th-Grade Teachers' Practices

The results of the $t$-tests for the 9th-grade teachers on the four constructs were not significant. Each construct had a maximum possible score of 20 points (based on a 5point Likert scale for each of the four items grouped together for each construct). Table 9 shows the means and standard errors for both groups. The experimental groups' mean on the Higher Order Thinking construct $(\mathrm{M}=11.8)$ was not significantly different than the comparison groups' mean $(\mathrm{M}=12.4), t(11)=.35, p=.535$. For the Cooperative Learning Groups construct, the experimental groups' mean $(\mathrm{M}=9.0)$ was not significantly different than the comparison groups' mean $(\mathrm{M}=9.6), t(11)=.21, p=.151$. For the Communication construct, the experimental groups' mean $(\mathrm{M}=11.0)$ was not significantly different than the comparison groups' mean $(\mathrm{M}=12.4), t(11)=.70, p=$ .233. For the Alternative Assessment construct, the experimental groups' mean ( $M=4.8)$ was not significantly different than the comparison groups' mean $(\mathrm{M}=7.8), t(11)=1.52$, $p=.602$. 
Table 9

Mean Scores of the Classroom Observation Protocol (COP) of Ninth-Grade Teachers

\begin{tabular}{lcccc}
\hline & \multicolumn{2}{c}{$\begin{array}{c}\text { Experimental Group } \\
(n=8)\end{array}$} & \multicolumn{2}{c}{$\begin{array}{c}\text { Comparison Group } \\
(n=5)\end{array}$} \\
\cline { 2 - 5 } COP Constructs & $M$ & $S E$ & $M$ & $S E$ \\
\hline Higher Order Thinking & 11.8 & 0.95 & 12.4 & 1.78 \\
Cooperative Learning Groups & 9.0 & 1.40 & 9.6 & 2.79 \\
Communication & 11.0 & 1.34 & 12.4 & 1.32 \\
Alternative Assessment & 4.8 & 1.09 & 7.8 & 1.85 \\
\hline
\end{tabular}

Note. Each construct had a maximum possible score of 20 points.

Classroom Observation Protocol (COP) for 10th-Grade Teachers' Practices

The results of the $t$-tests for the 10th-grade teachers on the four constructs were not significant. Table 10 shows the means and standard errors for both groups. The experimental groups' mean on the Higher Order Thinking, construct $(\mathrm{M}=12.4)$ was not significantly different than the comparison groups' mean $(\mathrm{M}=12.5), t(9)=.06, p=.930$. For the Cooperative Learning Groups construct, the experimental groups' mean ( $\mathrm{M}=$ $10.0)$ was not significantly different than the comparison groups' mean $(\mathrm{M}=9.0), t(9)=$ $.27, p=.131$. For the Communication construct, the experimental groups' mean $(\mathrm{M}=$ 11.8) was not significantly different than the comparison groups' mean $(\mathrm{M}=11.3), t(9)=$ $.20, p=.722$. For the Alternative Assessment construct, the experimental groups' mean $(M=6.2)$ was not significantly different than the comparison groups' mean $(M=7.8)$, $t(9)=.68, p=.390$. 
Table 10

Mean Scores of the Classroom Observation Protocol (COP) of Tenth-Grade Teachers

\begin{tabular}{lcccc}
\hline & \multicolumn{2}{c}{$\begin{array}{c}\text { Experimental Group } \\
(n=5)\end{array}$} & \multicolumn{2}{c}{$\begin{array}{c}\text { Comparison Group } \\
(n=6)\end{array}$} \\
\cline { 2 - 5 } COP Constructs & $M$ & $S E$ & $M$ & $S E$ \\
\hline Higher Order Thinking & 12.4 & 1.17 & 12.5 & 1.23 \\
Cooperative Learning Groups & 10.0 & 2.07 & 9.0 & 2.86 \\
Communication & 11.8 & 1.77 & 11.3 & 1.54 \\
Alternative Assessment & 6.2 & 1.98 & 7.8 & 1.47 \\
\hline
\end{tabular}

Note. Each construct had a maximum possible score of 20 points.

Summary

This chapter presented the results of the statistical analyses that were used to answer the research questions. It included descriptive statistics (frequencies, percentages, means, and standard deviations), chi-square tests, analyses of covariance (ANCOVAs), and $t$-tests. The analyses were designed to determine whether standards-based curriculum and instruction, and the use of technology could increase student achievement for lowperforming students. Several ANCOVAs were conducted to evaluate the impact of the standards-based program and the use of technology on student achievement while $t$ tests were conducted to identify if there were significant effects for teacher practices.

With the district's second interim assessment as the dependent variable, the 9thgrade analyses revealed that the experimental group was significantly lower than the comparison group which was an unanticipated result. However, more than $55 \%$ of the 
9th-grade students in the experimental group rarely used the computer portion of the program (Table 8 ). The 10th-grade analyses showed that $99 \%$ of the students in the experimental group used the computer portion of the program regularly. The 10th-grade experimental group had significantly higher mean scores than the comparison group on the second interim assessment.

With the 2007 DSS growth as the dependent variable, the 9th-grade analyses showed there was no significant difference between the experimental and comparison group. The 10th-grade analyses revealed significant main group effects-the experimental group having significantly higher growth than the comparison group (Table 7).

With respect to the teaching practices as observed with the Classroom Observation Protocol (COP), $t$-tests were conducted on each of the four constructs. The results of the $t$-test for both the 9 th- and 10 th-grade teachers on the four constructs were not significant. The COP indicated that teachers in both the experimental and comparison groups used traditional instruction strategies in their classrooms. These results may have been due to the small sample sizes of the teachers. 


\section{CHAPTER V}

\section{SUMMARY}

In 2001, the No Child Left Behind Act was mandated by the Federal government to ensure that each student receives an equitable, high-quality education. However, there still exists an achievement gap between disadvantaged and minority students and their peers. The reasons for the low-performance can be categorized in the following areas: (a) inappropriate curricula, (b) ineffective instruction, (c) low-level classroom discourse, (d) poor student self-concept, (e) poor adjustment to schooling, and (f) prejudice. The Final Report of the National Mathematics Advisory Panel (2008) suggests that some of the most critical elements to improve student achievement are: (a) to provide a rigorous curriculum for all students, (b) to assist teachers with improving instruction, and (c) to establish strong accountability.

This study examined instructional practices that were rooted in standards-based mathematics reform initiatives to determine if they would improve student achievement on the part of low-performing students. New curricula, Carnegie Learning Cognitive Tutor ${ }^{\circledR}$, were provided for algebra and geometry students. The new curricula also supplemented traditional pedagogy with computer-assisted instruction. Mathematics teachers received ongoing professional development to help them implement the new curricula. In addition, teachers were provided with ongoing support to assist them with the transformation of the learning environments for students using standards-based practices.

To determine if the experimental group did significantly better on the district's mathematics interim assessment, analyses of covariance (ANCOVA) were conducted on 
the district's second interim mathematics assessment and the Developmental Scale Score (DSS) involving the Florida Comprehensive Assessment Test (FCAT). To determine if teacher variables had an impact on the experimental group, ANCOVA was utilized to measure the differences between experimental and comparison groups' test scores on the district's second interim mathematics assessment as a function of student background variables (FCAT level, gender, socioeconomic status [SES], limited English proficiency [LEP]). Test scores on the district's first interim mathematics assessment served as a covariate. To determine if the experimental group made higher learning gains, ANCOVA was utilized to measure the differences between experimental and comparison groups' DSS growth, as a function of student background variables, with test scores on the 2006 DSS serving as a covariate. Separate analyses were performed for 9th- and 10th-grade students.

\section{Discussion}

Research Question 1 Results

Is there a significant difference between the mathematics scores as measured by the district's second interim assessment of students taught by teachers using standards-based curriculum and students taught by teachers using a traditional curriculum?

With respect to Question 1, results from the analyses revealed that the 9th-grade experimental groups' adjusted mean for the second interim mathematics assessment was significantly lower than the comparison groups' mean which was an unanticipated result. However, in analyzing use of the technology, it was revealed that more than $55 \%$ of the 9th-grade students rarely used the computer portion of the program. This suggested that the implementation of the reform curriculum for the 9th-grade experimental group may 
have been more than a challenge for their teachers. In addition to this, the Classroom Observation Protocol (COP) also implied that the 9th-grade, experimental-group teachers maintained a traditional approach to instruction. The 9th-grade results suggested that the early implementation of the reform curriculum was done with limited fidelity.

There was also a main effect involving the FCAT Level, with the 9th-grade students in Level 2 having a second interim mathematics-assessment adjusted mean significantly higher than the students in Level 1 . However, this was moderated by the significant FCAT Level involving SES interaction. Holm's sequential Bonferroni pairwise comparisons procedure indicated that the FCAT Level 2 students, who were in the paid/not-applied-for lunch-status group, scored significantly higher than the FCAT Level 1 students in the paid/not-applied-for lunch-status group. At the secondary level, determining socio-economic status from information about students who receive free or reduced lunch should be used with caution. In many instances, eligible low-SES students never receive assistance because they simply do not complete their applications for a variety of reasons (failure to meet the deadline, lost applications, no parent signature).

For the 10th-grade students, the experimental groups' adjusted mean for the second interim mathematics assessment was significantly higher than the comparison groups' mean. Analysis of the use of technology showed that $99 \%$ of the students in the experimental group used the computer portion of the program regularly. This suggested that the implementation of the reform curriculum for the 10th-grade experimental group may have been more aligned to the expectations of the Carnegie Learning Cognitive Tutor ${ }^{\circledR}$ program. The Classroom Observation Protocol (COP) indicated that the 10thgrade experimental-group teachers still maintained a traditional approach to instruction. 
However, the significance of the 10th-grade, experimental-group results suggested that the reform curriculum had a positive impact on the student achievement.

There was also a main effect of FCAT level, with the students in Level 2 having a second interim, mathematics-assessment adjusted mean significantly higher than the students in Level 1. This was moderated by the significant FCAT Level involving LEP interaction. Holm's sequential Bonferroni comparisons indicated that in both the LEP and non-LEP student groups, FCAT Level 2 students scored significantly higher than FCAT Level 1 students respectively. However, the increase of FCAT Level 2 students over FCAT Level 1 students was significantly larger for the LEP students than for the nonLEP students. There was also a main effect of gender, with females scoring higher than males on the second interim assessment.

Research Question 2 Results

Is there a significant difference between the yearly growth in mathematics as measured by the Developmental Scale Score (DSS) of students taught by teachers using standards-based curriculum and students taught by teachers using a traditional curriculum?

With respect to Question 2, the results showed that the 9th-grade experimental groups' adjusted mean (adj $M=89.92$ ) for the 2007 DSS growth was numerically higher than the comparison groups' mean (adj $\mathrm{M}=69.63$ ) but was not significant. There was a main effect for SES that was moderated by a significant interaction between SES and the 2006 DSS. However, students receiving free and reduced lunch had a 2007 DSS adjusted growth mean which was not significantly different than that of the students not receiving free or reduced lunch when evaluating growth at the mean 2006 DSS mean. Additional analyses were conducted at the various quartiles to see if the experimental group's 2007 
DSS growth was significantly higher than that of the comparison group. The analyses revealed that there were no significant differences at the mean, the 25 th or 75 th percentile for the 9th- grade groups. These results still appeared to show that over an extended period, the 9th-grade experimental group may have experienced greater growth than the comparison group, further supporting the claim that the reform curriculum can have a positive impact on student achievement.

The 10th-grade experimental group mean (adj $M=102.25$ ) was significantly higher than the comparison group (adj $M=46.89)$ when evaluated at the 2006 DSS mean. Additional analyses were conducted at the various quartiles of 2006 DSS to see if the experimental group 2007 DSS growth was significantly higher than the comparison group. At the 25 th percentile, the 2007 DSS growth for the experimental group was significantly higher than the comparison group. However, at the median and 75 th percentile, the 2007 DSS growth means for the experimental group were not significantly higher than the comparison group. This may have been a result of the "ceiling effect" which implies that the students with higher 2006 DSS scores had a smaller range for growth in 2007. The results of the analyses of mathematics FCAT DSS outcomes indicated that students in the experimental group had significantly higher overall growth than those students in the comparison group who completed the traditional curriculum.

\section{Research Question 3 Results}

Is there a significant difference between the teaching practices as measured by the Classroom Observation Protocol (COP) of teachers using a standards-based curriculum and teachers using a traditional curriculum?

With respect to Question 3, results from the analyses revealed no significant difference between the teaching styles of the teachers in the experimental group and the 
comparison group. The COP was a Likert-scale instrument that measured the degree to which a set of teaching practices were evident in a classroom where standards-based mathematics was being taught. Four constructs were measured: higher-order thinking, cooperative learning groups, classroom discourse, and alternative assessment. The results of the $t$-tests for both the 9th- and 10th-grade teachers on the four constructs were not significant. The teachers in the experimental group continued to use traditional instructional methods even though they were given in-depth training on the use of standards-based instructional strategies.

In spite of the efforts to transform teaching, it is very difficult to change teachers' practices (Hiebert, 1999). To change instructional practices, teachers need sufficient planning time to collaborate with colleagues. The current structure of most urban high schools in the district, including the two in this study, does not provide uninterrupted collaborative time for their teachers. Moreover, many of the teachers give up their planning time to teach an additional class for an extra monetary supplement. These additional classes further decrease the time for collaboration (including those teachers in this study) during a school's normal planning time. The importance of changing teachers' practices and beliefs in helping low-performing students is well accepted. Therefore, as urban schools attempt to reform instruction, it is imperative that there are non-negotiable times set aside for daily uninterrupted collaborative planning for teachers to examine their own practices, their curriculum, and their students' progress.

\section{Limitations}

The study was limited to two large urban high schools that were predominantly composed of African-American students. Since there are many other urban high schools 
with a more varied population, the conclusions of the study were restricted to the samples in this project. Another limitation of the study was that there was no qualitative data collected about the students' attitudes. Therefore, the analysis could not report if the teachers' behaviors, the curriculum, or the use of technology had any correlation to the students' attitudes. A third limitation was that the study was restricted to only those students who had both district interim assessment scores and two consecutive years of DSS scores. This reduced the 9 th-grade population from 757 students to 461 students and the 10 th-grade population of 750 students to 423 students.

\section{Conclusions}

The review of the literature suggested that it was important to change curricula, instruction, assessment, and the classroom environment to impact student achievement. In this study, the traditional textbooks were replaced with the Cognitive Tutor ${ }^{\circledR}$ algebra and geometry curricula that used technology to complement teacher-directed instruction. The computer component had assessment directly built in to measure basic functional skills and facts as well as higher-order reasoning and problem-solving skills. This allowed for individualized learning paths for the students. The results of the analyses of the 2007 DSS growth scores indicated that students who completed Cognitive Tutor ${ }^{\circledR}$ were more likely to achieve higher overall scores than those students in the comparison group. Students from cognitive classes demonstrated higher DSS mean scores.

The experimental group with an appropriately implemented program had higher learning gains as determined by the students' 2007 mathematics DSS. The difference between teaching styles related to student achievement was not significant in this study. However, this project concludes that the use of standards-based curricula can have a 
significant impact on academic achievement of low-performing students. The cognitive demands of the reform curricula provided the low-performing students the opportunity to learn facts and skills as they experienced more abstract content. The findings support the idea that if the traditional curriculum is replaced with standards-based curriculum that is implemented as intended, low-performing students may make significant learning gains.

\section{Implications}

In this study, three facets of teaching and learning were examined; curricula, teaching practices, and the use of technology. Results of the statistical analyses revealed that teaching practices and the use of technology were not significant factors in the differences observed between the experimental group and the control group. There were also some questions about the fidelity of the implementation in the early stages with the 9th-grade group. However, it is reasonable to attribute some of the differences observed to the curricula used in this study. The most plausible reason for standards-based curricula contributing to improvement of low-performing students is that the instruction was focused on making meaning and drawing connections between mathematics and the real world. Brain research has shown that when new learning is easily comprehensible and can be connected to prior knowledge, there is substantially more cerebral activity followed by dramatically improved retention (Maguire, Frith, \& Morris, 1999). Therefore, regardless of the curriculum used, teachers should spend more time establishing meaning for students. To establish meaning, teachers must make connections to the world as students know it.

So as secondary schools begin to transform themselves in their efforts to improve academic achievement for all students, educational leaders in curriculum must consider 
the use of standards-based curricula in the mathematics classrooms. Standards-based curricula are designed to provide rich mathematical content that is aligned with the elements in the NCTM frameworks and which helps teachers to present concepts using sound pedagogical approaches. Singapore, one of the high-achieving mathematics countries reported by the TIMSS study, has textbooks that have none of the special features of American textbooks. Instead, the Singapore textbooks offer clear and straightforward presentations of the mathematical concepts and topics outlined, according to the national framework (The Final Report of the National Mathematics Advisory Panel, 2008). As the Third International Mathematics and Science Study (TIMSS) clearly indicates, the traditional U.S. textbooks lacked focus, did little to challenge students mathematically, and covered far too many topics with little depth.

In addition to the adoption of standards-based curricula, curriculum leaders need to provide professional learning for teachers as they transition to the new standards. To learn to teach mathematics as we were taught is very difficult. To learn to teach in the manner demanded by the standards-based curricula is even harder.

\section{Recommendations}

Future research should look at the impact of standards-based curricula on the attitudes of both students and teachers. Studies have shown that there is a link between self-confidence and academic success (House, 2000b), so it is important to know if the reform curricula produce an effect on student attitudes. In addition to this, teachers' beliefs, attitudes, and perceptions can be an obstacle when they try to develop a standards-based pedagogy in their own classrooms. Teacher efficacy has been correlated to significant variables such as classroom instructional strategies and willingness to 
embrace innovations (Ashton \& Webb, 1986). Therefore, it is important to understand how teachers perceive reform curricula.

This study should be replicated using four or more high schools that have a varied population to see if there are similar findings in other settings for low-performing students. With more schools, the study can control confounding factors that can result from analyzing only two schools. The replicated study should also focus on both the pros and cons of using standards-based curriculum. With any reform, new resources such as technology are included and can have an impact on the school and classroom. The study should also look at teachers' acceptance of the reform curriculum, the amount of time teachers need to spend in order to learn the new curriculum, and the time spent planning to implement the curriculum, because these factors can significantly impact the use of standards-based practices. Finally, the study should use hierarchical linear modeling (HLM) to control for the effects of teacher or classroom characteristics on average classroom or individual achievement. In addition, HLM analyses provide other benefits, such as modeling of cross-level interactions, which allows for more complex questions to be asked of the data. 


\section{REFERENCES}

Agresti, A. (1996). Introduction to categorical data analysis. New York: John Wiley and Sons.

Anderson, J. R. (2002). Spanning seven orders of magnitude: A challenge for cognitive modeling. Cognitive Science, 26, 85-115.

Anderson, J. R., Corbett, A. T., Koedinger, K. R., \& Pelletier, R. (1995). Cognitive tutors: Lessons learned. The Journal of the Learning Sciences, 4(2), 167-207.

Ashton, P. T., \& Webb, R. B. (1986). Making a difference: Teachers' sense of efficacy and student achievement. New York: Longman.

Aubrey, C. (1997). Mathematics teaching in the early years: An investigation of teachers' subject knowledge. London: Falmer Press.

Balfanz, R., \& Mac Iver, D. (2000). Transforming high-poverty urban middle schools into strong learning institutions: Lessons from the first five years of the talent development middle school. Journal of Education for Students Placed at Risk, 5(2), 137-158.

Baron, R., Tom, D., \& Cooper, H. (1985). Social class, race, and teacher expectations. In J. B. Dusek (Ed.), Teacher expectancies (pp. 251-269) Hillsdale, NJ: Lawrence Erlbaum.

Behr, M. J., Harel, G., Post, T., \& Lesh, R. (1992). Rational numbers, ratio, and proportion. In D. Grouws (Ed.), Handbook of research on mathematics teaching and learning: A project of the national council of teachers of mathematics (pp. 296-333). New York: Macmillan.

Bempechat, J., Graham, S. E., \& Jimenez, N. V. (1999). The socialization of achievement in poor and minority students: A comparative study. Journal of Cross-Cultural Psychology, 30(2), 139-158.

Berry, R. Q., III. (2003). Mathematics standards, cultural styles, and learning preferences: The plight and the promise of African American students. The Clearing House, $76(5), 244-249$.

Berry, R. Q., III, \& Ritz, J. M. (2004). Technology education-A resource for teaching mathematics. The Technology Teacher, 63(8), 20-24.

Boaler, J. (2002). Experiencing school mathematics: Traditional and reform approaches to teaching and their impact on student learning (Rev. ed.). Mahwah, NJ: Lawrence Erlbaum Associates. 
Bol, L., \& Berry, R. Q., III. (2005). Secondary mathematics teachers' perceptions of the achievement gap. High School Journal, 88(4), 32-45.

Bozick, R., \& Ingels, S. J. (2008). Mathematics coursetaking and achievement at the end of high school: Evidence from the education longitudinal study of 2002. National Center for Education Statistics, Institute of Education Sciences, U.S. Department of Education. Washington, DC.

Burns, M. (1998). Math: Facing an American phobia. Sausalito, CA: Math Solutions Publications.

Calderon, M. (1999). Teachers learning communities for cooperation in diverse settings. Theory into Practice, 38(2, Building Community through Cooperative Learning), 9499.

Carpenter, T. P., Franke, M. L., \& Jacobs, V. R. (1998). A longitudinal study of invention and understanding in children's multidigit addition and subtraction. Journal for Research in Mathematics Education, 29, 3-20.

Cobb, P., Wood, T. L., \& Yackel, E. (1991). Assessment of a problem-centered secondgrade mathematics project. Journal for Research in Mathematics Education, 22, 329.

Cook, T. D., \& Campbell, D. T. (1979). Quasi-experimentation: Design \& analysis issues for field settings. Chicago: Rand McNally College Publishing.

Corbett, A. T., \& Anderson, J. R. (1995). Knowledge tracing: Modeling the acquisition of procedural knowledge. User Modeling and User-Adapted Interaction, 4, 253-278.

Corbett, A. T., Koedinger, K. R., \& Anderson, J. R. (1997). Intelligent tutoring systems. In M. G. Helander, T. K. Landauer, \& P. Prabhu (Eds.), Handbook of humancomputer interaction (2nd ed., pp. 849-970). Amsterdam: Elsevier Science.

Czerniak, C. M. (1990). A study of self-efficacy, anxiety, and science knowledge in preservice elementary teachers. Atlanta, GA: National Association for Research in Science Teaching.

D'Ambrosio, B. S. (1995). Highlighting the humanistic dimensions of mathematics activity through classroom discourse. Mathematics Teacher, 88, 770-772.

Davis, R. B., Maher, C. A., \& Noddings, N. (1990). Suggestions for the improvement of mathematics education. Journal for Research in Mathematics Education:

Monograph 4. 
Davidson, N., \& Kroll, D. L. (1991). An overview of research on cooperative learning related to mathematics. Journal for Research in Mathematics Education, 22(5), 362365.

Dembo, M. H., \& Gibson, S. (1985). Teachers' sense of efficacy: An important factor in school improvement. The Elementary School Journal, 86, 173-184.

Dugdale, S. (2001). Order out of chaos: A spreadsheet excursion into a mathematical frontier. The Journal of Computers in Mathematics and Science Teaching, 20(4), 347-365.

Dunham, P. H., \& Dick, T. P. (1994). Research on graphing calculators. Mathematics Teacher, 87, 440-445.

Edge, O. P., \& Friedberg, S. H. (1984). Factors affecting achievement in the first course in calculus. The Journal of Experimental Education, 52, 136-140.

Fennema, E., Franke, M. L., \& Carpenter, T. P., Carey, D. (1993). Using children's mathematical knowledge in instruction. American Educational Research Journal, 30, 555-583.

Ferguson, R. F. (2003). Teachers' perceptions and expectations and the black-white test score gap. Urban Education, 38(4), 460-507.

Flanders, J. R. (1994). Textbooks, teachers, and the SIMS test. Journal for Research in Mathematics Education, 25, 260-278.

Fuchs, L. S., Fuchs, D., Karns, K., Hamlett, C., Katzaroff, M., \& Dutka, S. (1997). Effects of task-focused goals on low-achieving students with and without learning disabilities. American Educational Research Journal, 34, 513-543.

Fuson, K. C. (1997). Children's conceptual structures for multidigit numbers and methods of multidigit addition and subtraction. Journal for Research in Mathematics Education, 28(2), 130-162.

Good, T. L. (1993). New direction in research on teacher and student expectations. Midwestern Educational Researcher, 6(1), 7-10.

Grant, T. J., Hiebert, J., \& Wearne, D. (1998). Observing and teaching reform-minded lessons: What do teachers see? Journal of Mathematics Teacher Education, 1(2), 217-236.

Grouws, D. A., \& Cebulla, K. J. (2000). Elementary and middle school mathematics at the crossroads. Yearbook: National Society for the Study of Education, 99(2), 209255 . 
Haycock, K. (1998). Collaborative cultures, team planning and flexible scheduling. Emergency Librarian, 25(5), 28.

Hembree, R., \& Dessart, D. J. (1986). Effects of hand-held calculators in precollege mathematics education: A meta-analysis. Journal for Research in Mathematics Education, 17(3), 83-99.

Hiebert, J. (1999). Relationships between research and the NCTM standards. Journal for Research in Mathematics Education, 30(1), 3-19.

Hiebert, J. (1997). Making sense: Teaching and learning mathematics with understanding. Portsmouth, NH: Heinemann.

Hodson, D., \& Hodson, J. (1998). From constructivism to social constructivism: A Vygotskian perspective on teaching and learning science. School Science Review, 79(289), 33-41.

House, J. D. (1993). Achievement-related expectancies, academic self-concept, and mathematics performance of academically underprepared adolescent students. The Journal of Genetic Psychology, 154, 61-71.

House, J. D. (1995a). Noncognitive predictors of achievement in introductory college chemistry. Research in Higher Education, 36(4), 473-490.

House, J. D. (1995b). Noncognitive predictors of achievement in introductory college mathematics. Journal of College Student Development, 36, 171-181.

House, J. D. (1995c). The predictive relationship between academic self-concept, achievement expectancies, and grade performance in college calculus. The Journal of Social Psychology, 135, 111-112.

House, J. D. (2000a). Academic background and self-beliefs as predictors of student grade performance in science, engineering and mathematics. International Journal of Instructional Media, 27(2), 207-220.

House, J. D. (2000b). The effect of student involvement on the development of academic self-concept. The Journal of Social Psychology, 140(2), 261-263.

Jiang, Z., \& McClintock, E. (2000). Multiple approaches to problem solving and the use of technology. The Journal of Computers in Mathematics and Science Teaching, 19(1), 7-20.

Jussium, L., Eccles, J., \& Madon, S. (1996). Social perceptions, social stereotypes, and teacher expectations: Accuracy and the quest for the powerful self-fulfilling prophecy. Advances in Experimental Social Psychology, 28, 281-287. 
Kamii, C., \& Lewis, B. A. (1990). Research into practice. constructivist learning and teaching. Arithmetic Teacher, 38(1), 34-35.

Knapp, N. F., \& Peterson, P. L. (1995). Teachers' interpretations of "CGI" after four years: Meanings and practices. Journal for Research in Mathematics Education, 26, 40-65.

Kober, N. (2001, April). It takes more than testing: Closing the achievement gap. A report of the Center on Education Policy. Washington, DC: Center on Education Policy.

Koedinger, K. R., Anderson, J. R., Hadley, W. H., \& Mark, M. (1997). Intelligent tutoring goes to school in the big city. International Journal of Artificial Intelligence in Education, 8, 30-34.

Leinwand, S. (1996). Capturing and sharing success stories. NCSM Newsletter, 25, 1-2.

Lloyd, G. M., \& Wilson, M. (2001). Offering prospective teachers tools to connect theory and practice: Hypermedia in mathematics teacher education. Journal of Technology and Teacher Education, 9(4), 497-518.

Love, N. (2002). Using data-getting results: Collaborative inquiry for school-based mathematics and science reform. Cambridge, MA: Christopher-Gordon.

Ma, L. (1999). Knowing and teaching elementary mathematics: Teachers' understanding of fundamental mathematics in China and the United States. Mahwah, NJ: Lawrence Erlbaum Associates.

Mack, N. K. (1990). Learning fractions with understanding: Building on informal knowledge. Journal for Research in Mathematics Education, 21, 16-32.

MacLennan, R. N. (1993). Interrater reliability with SPSS for Windows 5.0. The American Statistician, 47(5), 292.

Maguire, E. A., Frith, C. D., \& Morris, R. G. M., (1999). The fictional neuroanatomy of comprehension and memory: The importance of prior knowledge. Brain, 122, 18391850 .

Marshall, J. (2003). Math wars: Taking sides. Phi Delta Kappan. 85(3), 193-200,249.

Marzano, R. J. (2003). What works in schools: Translating research into action. ASCD, VA.

Maurer, S. B. (2000). College entrance mathematics in the year 2000--what came true? Mathematics Teacher, 93(6), 455-459. 
Miami-Dade County Public Schools. (2006). Statistical highlights 2005-2006.

Retrieved June 11, 2007, from

http://drs.dadeschools.net/Highlights/Highlights_2005-06.pdf

Meece, J. L., Parsons, J. E., Kaczala, C. M., Goff, S. B., \& Futterman, R. (1982). Sex differences in math achievement: Toward a model of academic choice.

Psychological Bulletin, 91, 324-348.

Morgan, P., \& Ritter, S. (2002). An experimental study of the effects of cognitive tutor alegbra I on student knowledge and attitude. Pittsburgh. Retrieved March 2007, from http://www.carnegielearning.com/web_docs/morgan_ritter_2002.pdf

Moses, R. P., \& Cobb, C. E. (2001). Radical equations: Math literacy and civil rights. Boston: Beacon Press.

Murray, H., Olivier, A., \& Human, P. (1998). Learning through problem solving. (ERIC Document Reproduction Services No. ED458096)

National Council of Teachers of Mathematics. (1989). Curriculum and evaluation standards for school mathematics. Reston, VA: Author.

National Council of Teachers of Mathematics. (1991). Professional standards for teaching mathematics. Reston, VA: Author.

National Council of Teachers of Mathematics. (1995). Assessment standards for school mathematics. Reston, VA: Author.

National Council of Teachers of Mathematics. (2000). Principles and standards for school mathematics. Reston, VA: Author.

National Research Council. (2003). Technology and assessment: Thinking ahead -Proceedings from a workshop. Washington, DC: National Academy Press.

Niess, M. L., Erickson, D. K., \& Oregon State Univ., Corvallis. Coll. of Science. (1992). The Oregon mathematics teachers of middle school mathematics project. A curriculum development and leader training project for middle school teachers of mathematics. Final Report. (ERIC Document Reproduction Service No. ED349170)

Newell, A. (1990). Unified theories of cognition. Cambridge, MA: Harvard University Press.

Noddings, N. (2005). What does it mean to educate the whole child? Educational Leadership. 63(1), 8-13. 
O'Day, J., \& Bitter, C. (2003, June). Evaluation study of the immediate intervention' underperforming schools program and the high achieving/improving schools program of the Public Schools Accountability Act of 1999 (Final report). Sacramento: California Department of Education, Policy and Evaluation.

Papanastasiou, E. C., \& Ferdig, R. E. (2006). Computer use and mathematical literacy: An analysis of existing and potential relationships. Journal of Computers in Mathematics and Science Teaching, 24(5), 361-372.

Pesek, D., \& Kirshner, D. (2000). Interference of instrumental instruction in subsequent relational learning. Journal for Research in Mathematics Education, 31(5), 524-540.

Peterson, P. L. (1988). Teachers' and students' cognitional knowledge for classroom teaching and learning. Educational Researcher, 17, 5-14.

Riordan, J. E., \& Noyce, P. E. (2001). The impact of two standards-based mathematics curricula on student achievement in Massachusetts. Journal for Research in Mathematics Education, 32(4), 368-398.

Robinson, E. E., Robinson, M. F., \& Maceli, J. C. (2000). The impact of standards-based instructional materials in mathematics in the classroom. Yearbook (National Council of Teachers of Mathematics), 2000, 112-126.

Rowan, B., Chiang, F., \& Miller, R. J. (1997). Using research on employees' performance to study the effects of teachers on students' achievement. Sociology of Education, $70(29), 256-258$.

Schmidt, W.H., McKnight, C.C., Cogan, L.S., Jakwerth, P.M., \& Houang, R.T. (1999). Facing the consequences: Using TIMSS for a closer look at US mathematics and science education. Dordrecht: Kluwer Academic Publishers.

Schoen, H. L., Hirsch, C. R., \& Ziebarth, S. W. (1998). An emerging profile of the mathematical achievement of students in the core-plus mathematics project access. (ERIC Document Reproduction Services No. ED420 518)

Schoenfeld, A. H. (2002). Making mathematics work for all children: Issues of standards, testing, and equity. Educational Researcher, 31(1), 13-25.

Schoenfeld, A. H. (2004). The math wars. Educational Policy. 18(1), 253-286.

Secada, W. G. (1992). Race, ethnicity, social class, language and achievement in mathematics. In D. Grouws (Ed.), Handbook of research on mathematics teaching and learning: A project of the National Council of Teachers of Mathematics (pp. 146-164). New York: Macmillan. 
Secada, W. G., Fennema, E., \& Byrd, L. (1995). New directions for equity in mathematics education. Cambridge, NY: Cambridge University Press.

Shulman, L. S. (1986). Those who understand: Knowledge growth in teaching. Educational Researcher, 15, 4-14.

Silver, E. A., \& Stein, M. K. (1996). The QUASAR project: The "revolution of the possible" in mathematics instructional reform in urban middle schools. Urban Education, 30(4), 476-521.

Slavin, R. E. (1990). Achievement effects of ability grouping in secondary schools: A best-evidence synthesis. Review of Educational Research, 60, 471-507.

Stage, E. K., \& Kloosterman, P. (1995). Gender, beliefs, and achievement in remedial college-level mathematics. Journal of Higher Education, 66, 294-311.

Steele, D. F. (1999). Learning mathematical language in the zone of proximal development. Teaching Children Mathematics, 6(1), 38-42.

Steen, L. A. (2002). Achieving mathematical proficiency for all: Moving beyond the math wars. College Board Review. No. 196 (Spring 2002), 4-11.

Taylor, P. M., Campbell, L. N., \& Long, V. M. (2001). Using math attack to balance the equation for middle school mathematics. Middle School Journal, 32(3), 43-50.

Tenenbaum, H. R., \& Ruck, M. D. (2007). Are teachers' expectations different for racial minority than for European American students? A meta-analysis. Journal of Educational Psychology, 99(2), 253-273.

Thompson, C. L., O'Quinn, S. D.,III, \& North Carolina Education Research Council. (2001). Eliminating the black-white achievement gap: A summary of research. Chapel Hill: North Carolina Education Research Council (ERIC Document Reproduction Service No. ED457250)

Tileston, D. W. (2004). 10 best teaching practices: How brain research, learning styles, and standards define teaching competencies. Thousand Oaks, CA: Corwin Press.

U.S. Department of Education. (1999). Exemplary and promising mathematics programs. Washington, DC: Author.

U.S. Department of Education. (2008). The final report of the national mathematics advisory panel. Washington, DC: Author.

Valverde, G. A., \& Schmidt, W. H. (1997). Refocusing U.S. math and science education. Issues in Science and Technology, 14(7), 60-62. 
VanDeMark, C. L. (1983). Implementation of microcomputers in the classroom:

Problems and potentials. (ERIC Document Reproduction Services No. ED234749)

Vogler, K. E. (2002). The impact of high-stakes, state-mandated performance assessment on teachers' instructional practices. Education, 123(1), 39-55.

Vygotskii, L. S., \& Kozulin, A. (1986). Thought and language [Myshlenie i rech. English.] (Rev. ed.). Cambridge, MA: MIT Press.

Wearne, D., \& Hiebert, J. (1988). A cognitive approach to meaningful mathematics instruction: Testing a local theory using decimal numbers. Journal for Research in Mathematics Education, 19, 371-384.

Webb, N. M. (1991). Task-related verbal interaction and mathematics learning in small groups. Journal for Research in Mathematics Education, 22, 366-389.

Weiss, I. R. (1997). The status of science and mathematics teaching in the United States: Comparing teacher views and classroom practice to national standards. ERS Spectrum, 15(3), 34-39.

Wenta, R. G. (2000). Efficacy of preservice elementary mathematics teachers. (Doctoral dissertation, Indiana University). Retrieved June 17, 2006, from ProQuest Digital Dissertations database. (Publication No. AAT 9999230).

Wheat, J., Tunnell, J. W., \& Munday, R. (1991). Predicting success in college algebra: Student attitude and prior achievement. College Student Journal, 25, 240-244.

White, P., Gamoran, A., \& Smithson, J. (1995). Math innovations and student achievement in seven high schools in California and New York. Madison: Consortium for Policy Research in Education and the Wisconsin Center for Education Research, University of Wisconsin.

Wilson, M. R., \& Krapfl, C. M. (1994). The impact of graphics calculators on students' understanding of function. The Journal of Computers in Mathematics and Science Teaching, 13(3), 252-264.

Woolfolk, A. E., \& Hoy, W. K. (1990). Prospective teachers' sense of efficacy and beliefs about control. (motivation and efficacy). Journal of Educational Psychology, 82(11), 81-83.

Yackel, E., Cobb, P., \& Wood, T. L. (1991). Small-group interactions as a source of learning opportunities in second-grade mathematics. Journal for Research in Mathematics Education, 22, 390-408. 
APPENDICES 
Appendix A: Classroom Observation Protocol 


\section{CLASSROOM OBSERVATION PROTOCOL}

Reprinted from TERC, CAMS, from CAMS Evaluation MR Classroom Observation Protocol by Steven Cohen.

Following is a set of practices we would expect to see in a classroom where Framework-Aligned Mathematics is being taught. Note that not all practices are appropriate in every lesson. Rate each of these practices on a scale from 1 to 5 and indicate the rating in the space to the left of each practice.

\section{School:}

Teacher:

Class/Grade:

1

not

observed
2

3

some
4

5

observed a

great deal

Curricular materials are selected that are challenging as well as accessible to all students.

There is a balance of higher-order thinking and mathematical reasoning, development of conceptual understanding, and skill building in small group discussion and work.

There is a balance of higher-order thinking and mathematical reasoning, development of conceptual understanding, and skill building in whole class discussion and work.

Students are expected to explain their thinking and share their ideas.

Students work in small, heterogeneous groups to maximize opportunities for meaningful learning.

Teachers give instruction in and reinforce cooperative learning strategies. 


\section{CLASSROOM OBSERVATION PROTOCOL}

Reprinted from TERC, CAMS, from CAMS Evaluation MR Classroom Observation Protocol by Steven Cohen.

Groups are diverse in terms of gender, language, ethnicity, and "ability."

*Groups give presentations to the class on their findings during group investigations, often using posters or models.

Calculators, manipulatives, and other materials are available at all times.

*Students are asked to communicate their understandings both orally and in writing.

There are concluding discussions in which students take the lead or play a highly significant role.

*Individually, students are given opportunities to demonstrate mathematical growth by doing quality large-scale work that is complete in that it demonstrates mathematical power through: higher-order mathematical thinking, clear communication using multiple ways of representing ideas, mathematics content, and appropriate mathematical tools and techniques.

*Assessment is used to evaluate student work, and not students.

*There is a tradition of draft, feedback, and revision for submitted written work.

*Portfolios of student work are periodically reviewed and refined.

Students develop their own algorithms.

*These items may be difficult to assess during a single observation. If possible, double check these items with teacher and student responses during interviews. 
Appendix B: Classroom Observation Protocol Constructs 


\section{Classroom Observation Protocol Constructs}

\section{Higher Order Thinking}

Curricular materials are selected that are challenging as well as accessible to all students.

There is a balance of higher-order thinking and mathematical reasoning, development of conceptual understanding, and skill building in small group discussion and work.

There is a balance of higher-order thinking and mathematical reasoning, development of conceptual understanding, and skill building in whole class discussion and work.

Students develop their own algorithms.

\section{Cooperative Learning Groups}

Students work in small, heterogeneous groups to maximize opportunities for meaningful learning.

Teachers give instruction in and reinforce cooperative learning strategies.

Groups are diverse in terms of gender, language, ethnicity, and "ability."

${ }^{*}$ Groups give presentations to the class on their findings during group investigations, often using posters or models.

\section{Communication}

*Individually, students are given opportunities to demonstrate mathematical growth by doing quality large-scale work that is complete in that it demonstrates mathematical power through: higher-order mathematical thinking, clear communication using multiple ways of representing ideas, mathematics content, and appropriate mathematical tools and techniques.

Students are expected to explain their thinking and share their ideas.

*Students are asked to communicate their understandings both orally and in writing. 


\section{Classroom Observation Protocol Constructs}

There are concluding discussions in which students take the lead or play a highly significant role.

\section{Alternative Assessment}

*Assessment is used to evaluate student work, and not students.

*There is a tradition of draft, feedback, and revision for submitted written work.

*Portfolios of student work are periodically reviewed and refined.

Calculators, manipulatives, and other materials are available at all times.

*These items may be difficult to assess during a single observation. If possible, double check these items with teacher and student responses during interviews. 


\section{VITA}

\section{MARCUS V. ANGLIN}

EDUCATION

2001

Ed. S., Curriculum \& Instruction in Mathematics Education Florida State University

Tallahassee, Florida

1999

M. S., Computer Education

Nova Southeastern University

Fort Lauderdale, Florida

1987

B. S., Applied Mathematics

University of Miami

Miami, Florida

PROFESSIONAL/ LEADERSHIP EXPERIENCE

2005 to present: District Supervisor, Mathematics Department

Miami-Dade County Public Schools

1999 to 2005 District Supervisor, Title I Administration

Miami-Dade County Public Schools

1996-1999

SECME Inc., Coordinator, Division of Mathematics

Miami-Dade County Public Schools

$1990-1992$

Mathematics and ESOL Teacher

Lindsey Hopkins Technical Center

$1999-2000$

Member of Department of Education FCAT Committee Jacksonville, Florida

1997

Member of Competency-Based Curriculum (CBC) Committee Miami-Dade County Public Schools

1992-1996

Mathematics Instructor

Miami Sunset Senior High School

$1995-1996$

Chairman of the Technology Committee

Miami Sunset Senior High School

1995

Coordinator of the Competency-Based Curriculum Initiative Miami Sunset Senior High School 